\title{
Changes in Body Condition from Prepartum to Postpartum on Health and Reproduction in Dairy Cattle
}

\author{
Keli Ann Akers \\ West Virginia University
}

Follow this and additional works at: https://researchrepository.wvu.edu/etd

\section{Recommended Citation}

Akers, Keli Ann, "Changes in Body Condition from Prepartum to Postpartum on Health and Reproduction in Dairy Cattle" (2014). Graduate Theses, Dissertations, and Problem Reports. 414.

https://researchrepository.wvu.edu/etd/414

This Thesis is protected by copyright and/or related rights. It has been brought to you by the The Research Repository @ WVU with permission from the rights-holder(s). You are free to use this Thesis in any way that is permitted by the copyright and related rights legislation that applies to your use. For other uses you must obtain permission from the rights-holder(s) directly, unless additional rights are indicated by a Creative Commons license in the record and/ or on the work itself. This Thesis has been accepted for inclusion in WVU Graduate Theses, Dissertations, and Problem Reports collection by an authorized administrator of The Research Repository @ WVU. For more information, please contact researchrepository@mail.wvu.edu. 
Changes in Body Condition from Prepartum to Postpartum on Health and Reproduction in Dairy Cattle

Keli Ann Akers

Thesis submitted to the

Davis College of Agriculture, Natural Resources and Design

at West Virginia University

in Partial Fulfillment of the Requirements

for the Degree of

Master of Science

in

Reproductive Physiology

Robert A. Dailey, Ph.D., Chair

E. Keith Inskeep, Ph.D.

Joseph W. McFadden, Ph.D.

Davis College of Agriculture, Natural Resources and Design

Morgantown, West Virginia

2014

Keywords:

Dairy Cattle, Reproductive Success, Negative Energy Balance, Stress, Nutritional Deficiencies, Embryonic Loss

Copyright 2014 Keli Ann Akers 


\section{ABSTRACT \\ Changes in Body Condition from Prepartum to Postpartum on Health and Reproduction in Dairy Cattle}

Keli Ann Akers

The aim of this study were to body condition score, 72 Holstein-Friesian dairy cows at prepartum, compare lean, moderate, and over-conditioned categories, and relate any changes associated with the various time points with reproductive success by measuring body condition score, hematocrit, total white blood cell (WBC) differential, haptoglobin (Hp) concentrations, milk yield and monitoring health status. The body condition score changed significantly with time with the greatest unit loss being in the over-conditioned cattle from d -30 to d 35 postpartum. The BCS losses for each category did not have a significant effect on reproductive success at any time. Health disorders were significantly related to parity. The health status had at $\mathrm{d} 0$ to 10 and during pre-breeding (d 20 to 26) postpartum had a significant effect on reproductive success. The hematocrit values were significantly reduced at d 20 to 26 postpartum. Pregnancy success was associated with $\mathrm{Hp}$ and milk yield with higher Hp concentrations and higher milk yield having the highest pregnancy rate. The white blood cell differential count was significantly different at certain sampling time points for monocytes, total neutrophils, and eosinophils; with the highest concentration for each at parturition. Lymphocyte concentrations did not differ. The study revealed that body condition, hematocrit, and parity were not good indicators of reproductive success. Parity of an animal had no effect on reproductive success but its association with prevalence of disease and health disorders in early postpartum decreased pregnancy success to first artificial insemination. Likelihood of successful pregnancy was high if both Hp and milk yield were high. The WBC counts portrayed lower than normal concentrations of lymphocytes and elevated levels of total neutrophils. 


\section{ACKNOWLEDGEMENTS}

I would like to start out by thanking my mentor Dr. Robert E. Dailey for always keeping a positive attitude and possessing such a great interest in the student learning process. Your love of the dairy cow stands strong and I hope this project has advanced the understanding of such a complex animal. I will always be grateful for all of the knowledge you have provided to me.

I have to thank all the teachers I have participated in courses with. Especially Dr. Inskeep and Dr. Minch, your knowledge base and ability to explain ideas with patience and understanding allow for a greater learning process. I want to thank my former and current graduate students for assistance during the study; Angela Santin, Eduardo Rico, and Ethan Bloomfield, you three were such a great help and drive during the high and low times of the study. I want to thank all the students and faculty within the Animal and Nutritional Sciences for assisting me whenever I needed it.

Thank you to the DoVan farm, family, and workers without you my project would not have happened. The great amount of assistance and hospitality I received will always be remembered.

I want to thank my family for the support and encouragement during my last two years. A special thanks to my late grandfather, Hobert B. Akers who always encouraged me to go after what I wanted in life. He taught me to have a strong work ethic and a hard head to help me when times were tough.

Finally, I want to thank the veterinarian, Dr. Arthur G. Wills I worked with for many years. You were the guidance for my interests in pursuing animal and veterinary science. I am forever grateful for having you as a teacher and friend. The experiences I received with you will always be instilled in my work. 


\section{Table of Contents}

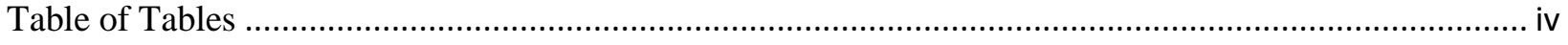

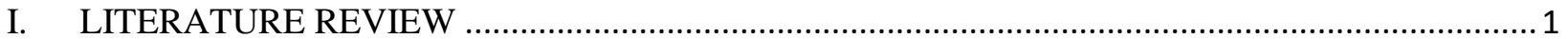

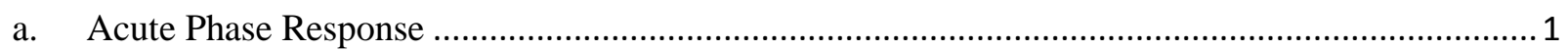

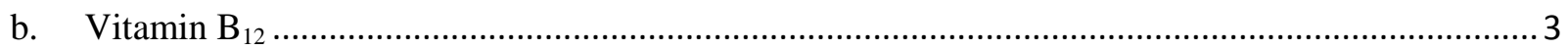

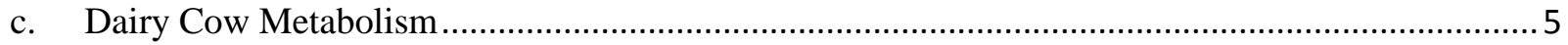

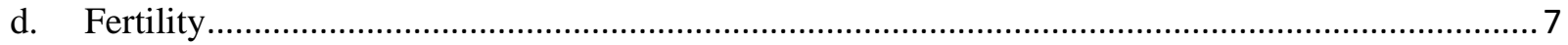

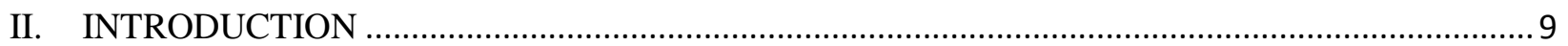

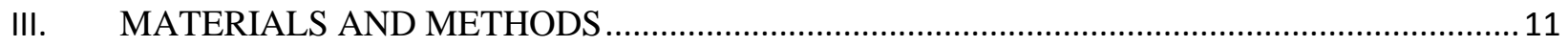

a. Milk Production and Health Summaries …........................................................................ 12

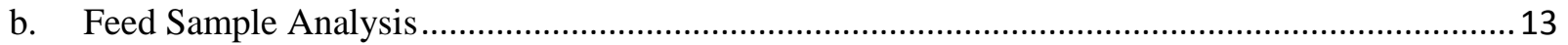

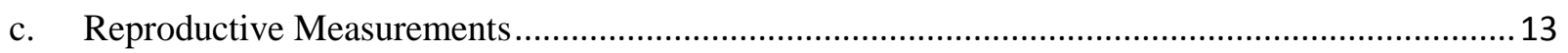

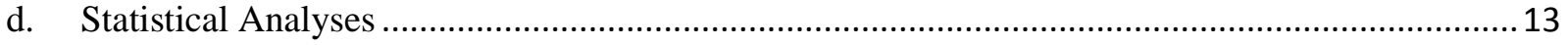

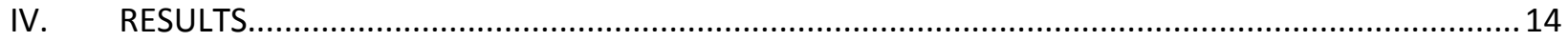

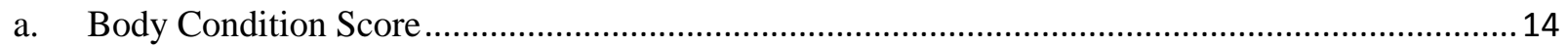

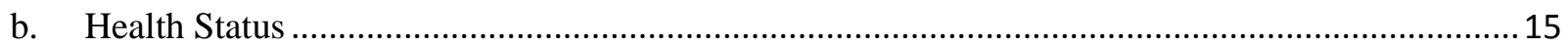

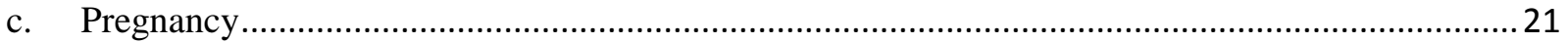

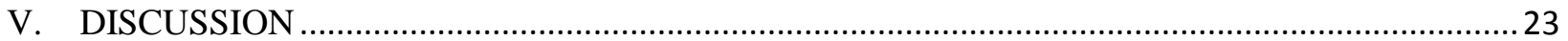




\section{Table of Figures}

Figure 1. Least square means body condition score (BCS) means $( \pm \mathrm{SE})$ at various time-points for cows categorized as lean, moderate, or over-conditioned 45 days prepartum through pregnancy

Figure 2. Comparison of BCS loss between d -30 prepartum and d 21 to 26 (pre-breed)

postpartum within lean, moderate, and over-conditioned cows ( $\mathrm{p}=0.0001)$... 15

Figure 3. Mosaic plot of contingency analysis of pregnancy status by first $10 \mathrm{D}$ following parturition all cows included for disease prevalence $(0=$ no disease, $1=$ diseased $) p$-value $=0.006$

Figure 4. Mosaic plot of contingency analysis of pregnancy status by pre-breeding time (20 to 26 d) all cows included for disease prevalence $(0=$ no disease, $1=$ diseased $)(p=<0.0001) \ldots \ldots . .17$ Figure 5. Contingency analysis of overall frequency of occurrences of disease $(0=$ healthy, $1=$ diseased) at any time as affected by parity $\left(\mathrm{X}^{2}=0.0111 \mathrm{p}=0.01\right)$

Figure 6. Hematocrits at prepartum (d -45), early postpartum (d 0 to 7), pre-breeding (d 20 to 26 ), and pregnancy check ( 26 to 32 days after insemination, mean $=95$ days postpartum $)(\mathrm{p}=$ $0.0001)$. 19

Figure 7. Repeated measures ANOVA of mean leukocyte cell counts $\left(10^{\wedge}{ }^{6}\right.$ per $\left.\mathrm{mL}\right)$ by BCS category (lean, moderate, and over-conditioned) for prepartum (d - 45), early postpartum ( 0 to 7), pre-breed (d 20 to 26), and pregnancy check ( 26 to $32 \mathrm{~d}$ after insemination, mean $=95 \mathrm{~d}$ postpartum) (no significance, $\mathrm{p}=0.7043$ ).

Figure 8. Repeated measures ANOVA of mean leukocyte counts $\left(10^{\wedge}{ }^{6}\right.$ per $\left.\mathrm{mL}\right)$ for prepartum $(\mathrm{d}$ -45 ), early postpartum ( 0 to 7 ), pre-breeding (d 20 to 26), and pregnancy check (26 to $32 \mathrm{~d}$ after insemination, mean $=95 \mathrm{~d}$ postpartum $)(\mathrm{p}$-values displayed in Table 3$)$ 20 Figure 9. Polynomial Fit (^3) log of Hp on d 20 to 26 by milk (kg/day) (The different shapes represent different quadrants $(\mathrm{p}=0.01$ ). Mean of $\operatorname{lnHp}$ is 3.9 and mean milk is $42.67 \mathrm{~kg} / \mathrm{day}$... 21 Figure 10. Distributions for second breeding DIM analysis using a nonparametric method (Kruskal-Wallis test).

Figure 11. Contingency analysis of pregnancy percentage by concentrations of haptoglobin and average milk production ( $\mathrm{d} 20$ to $26 ; \mathrm{p}=0.0003$ ). 


\section{Table of Tables}

Table 1. Disease frequency by categorized health disorders over all time points..................... 12

Table 2. Feed sample analysis for far-off, close-up, and lactating groups.

Table 3. Tukey-Kramer analysis of differences of least square means p-values for the differing time points $[1=$ prepartum $(\mathrm{d}-45), 2=$ early postpartum (d 0 to 7 ), $3=$ pre-breed (d 20 to 26), and $4=$ pregnancy check (26 to 32 post insemination)]. 


\section{LITERATURE REVIEW}

The dairy industry has placed emphasis on the importance of milk production by genetically selecting for cows that portray high milk yields with little concern for other attributes. As a result, today's dairy herd undergoes a large negative energy balance (NEB) due to the high milk yields altering the available glucose for metabolism versus milk production. This NEB causes a decrease in reproductive performance, which is effected in various ways from the timing of conception, pregnancy rate, and maintaining the pregnancy to full term (Butler, 2012; Walsh et al., 2011). These changes are likely associated with lack of sufficient energy for the reproductive tract to function properly allowing for adequate hormone signaling and embryo survival.

During the transition from prepartum into lactation, the dairy cow is faced with low glucose availability; hence, she undergoes various metabolic changes to overcome this deficit (Grummer et al., 2004). The responses are defined as stress (Selye, 1936). The cow is releasing metabolic hormones to help regulate energy metabolism. The actions of these hormones are first implemented through cyclic adenosine monophosphate (cAMP; Acin-Perez et al., 2009). This second messenger molecule carries hormonal signals (e.g. glucagon and adrenaline) into the cytoplasm of various cells, helps regulate the amount of glucose (Squires, 2003). Low energy levels (increase in AMP and decrease in ATP) leads to the release of cortisol, the main stress hormone. The release of cortisol results in increasing concentrations of epinephrine (adrenaline), which elicit an increase in glucagon release from the pancreas. Glucagon and epinephrine are responsible for fatty acid oxidation, whereas in times of energy abundance the insulin concentration is greater allowing for fatty acid synthesis (Berg et al., 2001).

\section{a. Acute Phase Response}

During the stressful transition period in the dairy cow an acute phase response (APR) occurs and, as a result, activation of the hypothalamo-pituitary-adrenal (HPA) axis (Berezi et al., 2005). This response involves various changes including but not limited to inflammation, fever, and suppression of appetite. The APR is under the control of various cytokines used in signaling pathways, which are produced by macrophages as a defense mechanism for the animal facing stress or injury (Berezi et al., 2005). The immune system begins to release cytokines such as, tumor necrosis factor alpha (TNF $\alpha$ ), interleukin-1 (IL-1), and interleukin-6 (IL-6) causing an inflammatory response (Berezi et.al, 2005), insulin resistance via phosphorylation of insulin receptor substrate-1 (IRS-1), stimulation of corticotropin releasing hormone (CRH) from the hypothalamus (Li et al., 2007; Squires, 2003), and reduce feed intake (Yuan et al., 2013). Feed intake is regulated through stimulation of adipocytes, mechanical forces (stomach and small intestine), and actions of hormones When TNF $\alpha$ is secreted, an immune response is initiated causing lipolysis, prevents insulin and glucagon secretion and transduction, apoptosis and necrosis, as the name suggests (Beitz, 2014). TNF $\alpha$ also induces release of CRH leading to synthesis of cortisol and other glucocorticoids, which can result in reduced reproductive function (Squires, 2003; Berezi et al., 2005). Glucocorticoids are secreted from the adrenal cortex to enhance glucose synthesis through gluconeogenesis and lipolysis of triglycerides (Squires, 2003; Uchoa et al., 2014). Cortisol is a glucocorticoid released during times of stress (Combs, 1998; Uchoa et al., 2014) and responsible for metabolism of proteins, fats and carbohydrates via 
breaking down the body's storage reservoirs (triglycerides and glycogen) in times of low blood glucose (Combs, 1998; Squires, 2003), as well as, initiating onset of lactation and glucose uptake in mammary tissue (Tucker, 2000). This is an important mechanism for the transition dairy cow during the last three weeks prepartum and first three weeks postpartum due to her inability to maintain sufficient glucose levels for lactation and body weight regulation as observed through body condition score (BCS).

The glucose requirements for lactation cause the cow to increase her dry matter intake (DMI) postpartum. However, high DMI does not negate the increasing demand for glucose during the first few weeks of lactation (Drackley, 2004). As a result, the cow will lose weight due to increased protein and fat catabolism during this NEB. The NEB is typically monitored by measuring the concentration of non-esterified fatty acids (NEFA) in blood samples. Under NEB, dairy cows show increased rates of NEFA due to increased lipolysis. The increased DMI causes great changes in the gastrointestinal tract that may negatively affect digestion. Many dairy farmers recognize the increasing need for energy in the transition cow and feed a higher ration of grains several weeks before parturition (close-up cows) to decrease the severity of the NEB (Rabelo et al., 2005). As a result, cows are shifted from a high fiber (cellulolytic) based diet during far off and late lactation (minimizing gain in body condition and feed costs within the herd) to a grain (high energy starch based) diet, which alters populations of microbial species and fermentation processes in the rumen (Ametaj, 2005; Khafipour et al., 2009; Esposito et al., 2014) and suppresses the immune system (Esposito et al., 2014). The concern with shifting the microbial populations to starch fermenters is that many of the ruminal bacteria are Gram negative and possess a high amount of lipopolysaccharides (LPS) in their membrane (Ametaj, 2005; Berezi, 2005). The LPS, also known as endotoxins, cause an immune response when the Gram negative bacteria are lysed (die) and release toxins into the bloodstream (Nagaraja et al., 1978).

Macrophages react to LPS by phagocytosis and release cytokines (i.e., TNF $\alpha$ ) and acute phase proteins (APP) (Ametaj, 2005; Berezi, 2005). The APPs are secreted from hepatocytes to ameliorate the effects of the endotoxin. One APP, serum amyloid A (SAA), is associated with lipoproteins and is responsible for recruitment of immune cells to inflammatory sites and enzymatic degradation and removal of endotoxins via the liver. The increase in endotoxins is thought to be one reason for the increased accumulation of lipids in the liver causing fatty liver syndrome in NEB cows due to increased fatty acid mobilization and triglyceride storage in the liver. Cows with fatty livers have increased incidences of metabolic diseases and conditions that decrease milk production, fertility rate, and overall health status (Ametaj, 2005; Ametaj et.al, 2010). Serum concentrations of another APP, haptoglobin (Hp), increase during inflammatory responses and are associated with fat mobilization into the parenchymal cells of the liver during fatty acid oxidation (Huzzey et al., 2011). The Hp, which also is found in dairy cattle adipose tissue is a positive APP that increases its function during APR and functions as an antioxidant (decreasing the oxidative stress) for erythrocytes by binding to hemoglobin (Ametaj, 2005; Berezi et al., 2005; Ebdalabadi et al., 2014).

Immunosuppression occurs in dairy cattle with oxidative stress placing a greater need for antioxidants to improve immune health (Bradford, 2012). In healthy cattle, the PMN usually represent $25 \%$ of the total leukocytes in the blood (Paape et al., 2003) and are the first line of defense during invasion of pathogens, such as in mastitis infection. The changes during bovine 
infections may depend on stress levels and fetal membranes along with invading pathogens (Jain, 1986). During parturition and the first few weeks after giving birth, the cow is faced with high concentrations of cortisol and NEFA due to parturition, milk production, and possible feed alterations. The stress often leads to an inflammatory response resulting in increased numbers of neutrophils in blood (O'Connor et al., 2000). As the inflammation progresses the neutrophil reserves decreases and immature (banded) neutrophils from the bone marrow are likely to enter into the blood, known as a left shift, which may depend on stress levels and fetal membranes along with invading pathogens (Jain, 1986). The inflammation associated with parturition and beginning of lactation often leads to increasing NEFAs and ROS, which can impair the function of immune cells (i.e. neutrophils), and by doing so, decrease tissue repair and removal of debris and bacteria from the uterus and mammary gland (Esposito et al., 2014; Krause et al., 2014).

\section{b. Vitamin $B_{12}$}

The increase in the immune response during high endotoxin concentrations increases the metabolic effects that are common in the transition dairy cow. The increase in metabolic response, which is thought to be induced by increasing grain diet in the transition cow, is likely to change the utilization of minerals, ruminal absorption, volatile fatty acid production, and $\mathrm{pH}$ (Ametaj et al., 2010; Esposito et al., 2014). The digestive function of these cows is greatly increased resulting in a higher demand for enzymes, responsible for breaking down the feed. The vitamin B complex plays a direct role in the catabolism of carbohydrates, proteins and fats during digestion. Vitamin $\mathrm{B}_{12}$ is required and can be synthesized by cobalt supplementation through ruminal microorganisms and escape of dietary sources from the rumen (Combs, 1998). Vitamin $B_{12}$ is associated with ruminant digestion in two ways: 1) methylmalonyl-CoA mutase is responsible for converting methylmalonyl CoA into succinyl-CoA, Coenzyme A is then removed leaving succinate, which enters the Krebs cycle during the degradation of propionate and 2) methionine synthetase is responsible for methylating homocysteine to produce methionine by transferring a methyl group from 5-methyl tetrahydrofolate to homocysteine (Akins, 2013; Combs, 1998; Matthews, 1999). Methionine can then be converted into S-adenosylmethionine (SAM) which is an important methylating intermediate in various pathways of synthesis, including but not limited to: 1.) converting epinephrine into metanephrine to help regulate stress by removing the buildup of adrenaline within the body, 2.) methylation of norepinephrine into epinephrine, which is regulated by corticosteroids and is involved in lipid metabolism, and 3.) conversion of lysine to $\varepsilon-\mathrm{N}$-trimethyllysine for carnitine synthesis. Carnitine is important in transporting long chain fatty acids from the cytosol into the mitochondria for beta oxidation (Miller, 2003; Berg, 2001).

With increasing DMI, the increased flow of ruminal fluids may lead to one or more vitamins becoming either unavailable due to alterations in the gastrointestinal tract not allowing for proper uptake and/or deficiency of the vitamin (Baird et al., 1972). By increasing DMI, the concentration of B vitamin biosynthesized by rumen microbes decreases (Weiss, 2006) which, indicates a higher amount of the vitamin is required to maintain normal concentrations. If a vitamin $\mathrm{B}_{12}$ deficiency is present in the cow it is likely that methylmalonyl-CoA or homocysteine will increase due to inhibiting the Krebs and methionine cycles leading to a disruption of acetyl CoA (main energy producing substrate in the ruminant) production (Combs, 1998).Vitamin $\mathrm{B}_{12}$, also known as cobalamin because it consists of a cobalt atom bound within the molecule, is synthesized by bacteria and is rarely found in plant derivatives except for some bean plants. In ruminants, vitamin $\mathrm{B}_{12}$ is produced after consumption of cobalt, which allows rumen bacteria to 
synthesize the vitamin $\mathrm{B}_{12}$. The suggested cobalt requirements for cattle through mineral supplementation are $0.11 \mathrm{mg} / \mathrm{kg}$ of DM (NRC, 2001). Dairy cattle are likely to have a greater requirement for cobalt based on optimal microbial action in the rumen and vitamin $\mathrm{B}_{12}$ concentrations in cattle (Weiss, 2005). The increase in the DMI postpartum due to lactation would indicate that an increase is required to maintain vitamin $\mathrm{B}_{12}$ concentrations. Multiparous cows possessed lower vitamin $\mathrm{B}_{12}$ concentrations compared to primiparous cattle, and its concentration decreased from 30 to 120 DIM (Weiss, 2005), which is indicative of a loss in cobalt availability that most likely disabled vitamin $\mathrm{B}_{12}$ production. A cobalt deficiency in ruminants led to altered lipid metabolism by decreasing enzymatic activity of methionine synthase and methylmalonyl-CoA mutase and increases the plasma concentrations of homocysteine and methylmalonic acid (Kennedy et al., 1994; Stangl et al., 2000).

A decrease in methionine synthase causes an inability to produce methionine for protein anabolism as well as its function as a methyl donor via SAM, which is a coenzyme for many methylations during chemical syntheses such as: carnitine, melatonin, methoxycatecholestradiols, metanephrine, protein methylation, and epinephrine (Miller, 2003; Berg et al., 2001). A methylmalonyl-CoA mutase deficiency would lead to decreased conversion of methylmalonyl-CoA into succinyl-CoA causing a shut down in the Krebs cycle and beta oxidation. A study performed by Basoglu et al. (2014) evaluated dairy cows with displaced abomasum (DA). The nuclear magnetic resonance (NMR) data displayed a great reduction in succinate in cows diagnosed with DA indicative of nutritional deficiencies. In the case of reduced vitamin $B_{12}$ deficiencies, concentrations of methylmalonyl-CoA were elevated, which inhibited the carnitine shuttle of fatty acids from the cytosol into the mitochondria leading to a decrease or inhibition in beta oxidation from occurring in the cells. This decrease likely leads to elevated free fatty acids unable to be oxidized, reduction in ATP production, and accumulation of free fatty acids in the liver.

Determining the nutritional requirements of a lactating dairy cow is difficult due to feed content variations and DMI. The bioavailability of the cobalt supplement must be considered; using organic rather than inorganic cobalt supplementation would ideally allow for more adequate absorption resulting in greater vitamin $B_{12}$ concentrations (DeFrain et al., 2009). Tiffany (2003) showed that supplementing cobalt to finishing steers decreased plasma succinate and increased plasma concentrations of folate and glucose. Once vitamin $\mathrm{B}_{12}$ is produced by ruminal microorganisms it can be absorbed by binding to intrinsic factors which are $\mathrm{R}$ proteins produced by parietal cells in the gut (Combs, 1998) or through simple diffusion. The intrinsic factors and vitamin $\mathrm{B}_{12}$ complex decreases the likelihood of bacterial catabolism of the vitamin within the gut. The intrinsic factor can bind to its receptor in the ileum. A deficiency in intrinsic factor could lead to decreasing the availability of vitamin $\mathrm{B}_{12}$ (Combs, 1998). Once absorption occurs, vitamin B12 will be transported into the blood plasma and bind to proteins known as transcobalamins (Combs, 1998). Specific binding of vitamin $\mathrm{B}_{12}$ and transcobalamin complex involves transcobalamin receptors for cellular uptake within various tissues (Combs, 1998). Vitamin $\mathrm{B}_{12}$ has been found in greatest concentration in the pituitary gland, but most is stored in the liver (Combs, 1998). The metabolic changes that a dairy cow goes through pre and postpartum may lead to decreased vitamin $\mathrm{B}_{12}$ concentrations or inability to utilize available 
stores. Of note, diets having higher rumen fermentable matter (i.e. starch based diets) promote synthesis of many of the B vitamins but decrease vitamin $B_{12}$ production (Weiss et.al, 2010).

Vitamin $\mathrm{B}_{12}$ plays a role in the proper functioning of lipolysis in the liver. The dairy cow undergoes great stress during NEB due to the high energy demands of lactation. During peak lactation the cow will be using $80 \%$ of available glucose to produce milk (Wathes et al., 2013), which causes the liver to increase beta oxidation of fatty acids. NEFA mobilization can be measured by blood concentrations of NEFA; whereas, the measures of beta-hydroxybutyrate provides an indication of fatty acid oxidation (Wathes et al., 2013). Both are important in understanding the overall metabolic status of the cow. These fatty acids are activated (fatty acyl $\mathrm{CoA}$ ) and then carried to the mitochondria via carnitine shuttle for beta oxidation. A small percentage of the fatty acids (long chain fatty acids- LCFA) are carried to the peroxisomes. The mitochondria are responsible for converting these fatty acids into ATP for energy. When excessive fatty acid mobilization occurs, the mitochondria often become overloaded and produce reactive oxygen species (ROS), and the peroxisomes become more active alternatively producing hydrogen peroxide and heat (Wathes et al., 2013; Shaum et al., 2013). Excessive lipolysis overloads the liver and mitochondria causing lipid accumulation in these tissues likely leading to damage and apoptosis of the cells (Wathes et al., 2013; Shaum et al., 2013). Studies associated with obese women have shown that accumulation of lipids and oxidative stress in reproductive tissues, such as oocytes, causes a decrease in oocyte development (Shaum et al., 2013). The stress placed on the mitochondria during this high level of lipolysis in dairy cattle likely causes mitophagy, clearing of damaged mitochondria, due to shortage of nutrients and the oxidative stress placed on the mitochondria resulting in DNA damage and ultimate apoptosis of the organelle (Wathes et al., 2013). Antioxidants convert ROS into water and cofactors, such as vitamin $\mathrm{B}_{12}$, facilitate beta oxidation in the mitochondria to control this oxidative stress (Wathes et al., 2013; Shaum et al., 2013). Over/under conditioned dairy cattle were most susceptible to oxidative stress from lipolysis (Wathes et al., 2013). This result supports other findings indicating the importance of proper diet for the cattle during the various stages of their production and, an increasing need for studies to determine the effects on metabolism of minerals, such as cobalt, a key component of vitamin $\mathrm{B}_{12}$ in feed rations.

\section{c. Dairy Cow Metabolism}

Supplementing a balanced diet for vitamins and minerals associated with decreasing metabolic diseases is crucial. Vitamin D binding protein (DBP) assists in transport of fatty acids along with actin binding, macrophage activation, and binding of vitamin D (Speeckaert et al., 2006). Vitamin D regulates absorption of calcium and phosphorus in the intestine. During the few weeks of late pregnancy and early postpartum, the intestinal tract is under great flow increases and calcium losses due to lactation, which may cause either sub-clinical or clinical hypocalcaemia. Decreased calcium concentrations are associated with reduced smooth muscle function, rumen and abomasal motility, milk production, immune response, fertility, DMI, and higher incidence of lameness (Kimura et al., 2011; Oetzel and Miller, 2012). Ward et al. (1971) administered calcium boluses (300,000 IU) per week to cows and found that they reached estrus 16 days earlier and the days to conceive were reduced by 37 . Cows diagnosed with a uterine disease had lower plasma calcium concentrations likely due to calcium being the second messenger of PMN activation (Martinez-Patino et al., 2011). 
During NEB in dairy cows, fatty acids are transported into the liver and can be packaged into very low density lipoproteins (VLDL) and accumulate within the liver, or exported from the liver to other tissues for beta oxidation of triacylglycerides to form acetyl CoA to go into the Krebs Cycle or to ketones ( $\beta$-hydroxybutyrate) (Berg, 2001; Grummer, 2008; Loor, 2010). The VLDL likely goes to non-vital tissues such as reproductive organs. Leroy et al. (2005) showed the low density lipoproteins can be found in follicular fluid. Fatty acids provide an energy source at the cost of lipid accumulation and possible overloading of the cell's mitochondria resulting in oxidative stress to the organelles in these regions. The three main fatty acids observed in these dairy cows during NEB were oleic acid, palmitic acid, and stearic acid (Leroy, 2005). Fatty acid profiles differ between cows (higher) and heifer (lower) correlate with the lower fertility in the cow (Bender, 2010). Leroy et.al (2005) found that palmitic and stearic acid had negative effects on resumption of meiosis. Palmitic and stearic acids are common fatty acids found within the serum and follicular fluid of the transition dairy cow (Leroy, 2005; Bender, 2010), although the concentration within the two fluids differs (Bender, 2010). Granulosal cell toxicity and the increase in these two fatty acids have been correlated showing reduction in function occurs during high concentrations of palmitic and stearic acid (Leroy et.al, 2005). The effects that fatty acid mobilization has on the transitioning dairy herd i.e. insulin resistance and decreasing oocyte quality are important because the increase in mobilization of fatty acids is a known cause of insulin resistance. A study by Preis et al. (2005) revealed that oocytes that were able to take up and utilize glucose readily had increased fertilization rates. This implicates a direct role for insulin sensitivity in reproductive organs. Decreasing the NEFA concentrations during a cow's transition period would likely lead her to resume successful reproductive function. Ketosis often occurs in cows with severe NEB and is a highly correlated to slower reproductive resumption. Ketotic cows have an inadequate pattern of luteinizing hormone pulses leading to delay in time to ovulation; as well as, less immune response associated with delayed uterine involution and proper cleanup via macrophages and neutrophils (Grummer, 2008; Merck Animal Health, 2012). The accumulation of triacylglycerides leads to hepatocyte and mitochondrial damage (Wathes et al., 2013) as well as, what appears to be peripheral tissue damage and metabolic alteration (Leroy et al., 2005). The fatty acid outcomes are important in understanding the cow's energy status and reproductive health.

Increased NEFA concentrations during pre- and postpartum are associated with increased activation of peroxisomes due to the overload of LCFA in the mitochondria. This leads to mitochondria oxidation and decrease in ATP production versus heat production (Loor, 2010). Increasing LCFA can activate peroxisome proliferator-activated receptor (PPAR) isotypes; this nuclear receptor binds to a specific DNA sequence and has the ability to induce or repress expression (Bionaz et al., 2013; Loor, 2010). The knowledge that PPAR affects ruminants has not been confirmed; PPAR is important to lipolysis, lipogenesis, milk fat synthesis, and inflammatory responses, all of which are functions associated with the transition cow (Bionaz et al., 2013; Loor, 2010). Up-regulation of PPAR occurs with an increase in NEFAs in the blood (Bionaz et al., 2013), and PPARs are abundant in high catabolic adipose tissue in non-ruminants, which may be similar in ruminants, indicating a role in the beta oxidation process of transition dairy cattle (Bionaz et al., 2013). Recent studies have shown that nutrition of the dairy cow affects the ability of PPAR to become activated. Dairy cows fed high energy diets during pregnancy tended to have decreased activated PPARs early postpartum, which may reduce the positive effects that PPARs play in regulating genes associated with beta oxidation and insulin sensitivity (Bionaz et al., 2013). Non-ruminants with restricted diets or in fasting states have 
increased expression of PPAR activation (Bionaz et al., 2013). The direct roles that PPARs may play in fatty acid mobilization have not been described fully. However, the increases in PPAR and its known actions to decrease insulin sensitivity, promote oxidation via mitochondria and peroxisomes and, hence, decrease lipid accumulation, and decrease inflammatory responses from APR indicates a stronger demand for research in the ruminant (Bionaz et al., 2013; Loor, 2010). The various PPAR isotypes appear to have the ability to decrease the NEB observed in the transition cow due to their adaptive roles in gene regulation during the transition period.

The liver also plays a role in insulin-like growth factor-1 (IGF-1) production via growth hormone $(\mathrm{GH})$ and its receptor (GHR-1A) availability. During the shortage in glucose availability the dairy cow's body undergoes changes to decrease glucose consumption by nonessential tissues (Wathes et al., 2013). Insulin is responsible for glucose uptake and delivery to various target tissues for energy. During NEB in dairy cows, the adipocytes develop insulin resistance due to elevated lipid concentrations. High NEFAs in plasma cause phosphorylation of IRS-1 (Sinclair, 2010). Reduced insulin causes gluconeogenesis within the liver (Loor, 2010). Studies have shown that the lower the plasma glucose and the higher the NEFA concentrations the less likely a cow will either be cyclic or conceive by the first artificial insemination (Garverick et al., 2013). Garverick suggests that glucose and NEFA concentrations are coincidental with reproductive tissues undergoing involution and reinitiating cyclicity.

\section{d. Fertility}

The process of gluconeogenesis also causes the GH and IGF-1 axis to become uncoupled (loss of GHR-1A) causing suppression of IGF-1 production within the liver (Lucy, 2012). The uncoupling occurs due to glucocorticoids stimulating $\mathrm{GH}$ gene expression (O'Connor et al., 2000). IGF-1 is an important growth factor and acts as a negative feedback regulator for GH (Lucy, 2012). If stress signals are maintained over a long period of time, $\mathrm{GH}$ will be suppressed due to increased somatostatins (O'Connor et al., 2000) If the GHR-1A is down-regulated, it causes decreases in IGF-1 production. In vitro studies have shown that the bovine embryo has receptors for both recombinant bovine somatotrophin (rBST), a synthetic form of bovine $\mathrm{GH}$ and IGF-1 (Izadyar, et al., 1998; Hernandez Ceron et al., 2000). Upon adding rBST to the media, a greater number of embryos reached the blastocyst stage (Hernandez Ceronet al., 2000). Various researchers have used rBST to improve the conception rate of subfertile cows (Morales-Roura et al., 2001; Hernandez Ceron et al., 2000). Other in vitro work has shown that rBST accelerates nuclear maturation, increases cumulus expansion and promotes embryonic development (Kuzmina et al., 2007) as well as increased fertility rate (Izadyar et al., 1998). In lactating dairy cows, the concentration of GH are high compared to IGF-1 due to uncoupling, which is dependent on the NEB the cow is experiencing. The APR that occurs within the transition cow causes the increase in GH and prolactin (PRL) that is observed and results in inflammatory and immune responses (Berezi et al., 2005). However, in severe APR cases, these two hormones are suppressed and the increase in cytokine signaling and glucocorticoid production increases (Berezi et al., 2005; Ametaj et al., 2010). The idea is to replenish GHR within the liver to allow for IGF-1 production to resume and initiate transport to the reproductive target tissues. Elevating the plasma insulin concentration increased hepatic expression of GHR-1A and IGF-1 mRNA (Butler et al., 2003). When associated with reproductive tissues, IGF-1 stimulated the development of ovarian follicles (Butler, 2012). The developing follicles are dependent on insulin, GH, and IGF-1 for full maturation (Butler, 2012). The effects of fatty acid accumulation and ketone formation can cause a delay in the release of luteinizing hormone (LH) and follicle 
stimulating hormone (FSH), which are required to initiate proper follicle development and ovulation (Butler, 2012). When cows are under stress (high glucocorticoids) reproductive functions are suppressed by inhibiting $\mathrm{GnRH}$ secretion and proper functioning of the gonads (O’Connor et al., 2000).

The reduction in fertility of dairy cattle has been associated with genetic selection for milk yield rather than fertility. Khatib et al (2009) found specific genotypes portraying antagonistic roles between the two traits. Milk production is negatively correlated with conception to artificial insemination in lactating cows during high energy expenditure (Demetrio et al., 2007). Epigenetics focuses on inheritance of divergent gene expression without altering the DNA sequence (Kropp et al., 2014). Each parent is a factor in determining the gene expression of the embryo and it has been shown that reduction in metabolic status decreases embryonic development (Demetrio et al., 2007; Ramalho-Santos et al.,2009; Kropp et al., 2014). The importance of oocyte competence, fertilization, and ability to successfully divide through blastocyst stage are some of the many steps to successful embryonic development. For successful attachment and pregnancy the conceptus has to be able to release interferon tau (IFN $\tau$ ) prior to attaching to the endometrium of the uterus via caruncles attaching to the epitheliochorial placenta of trophoblast (Bauersachs and Wolf, 2013). The IFN $\tau$ assists in maintaining the corpus luteum (CL) which is responsible for the production of the pregnancy hormone, progesterone $\left(\mathrm{P}_{4}\right)$. In a non-pregnant cow, $\mathrm{P}_{4}$ is responsible for priming the hypothalamus to initiate estrogen $\left(\mathrm{E}_{2}\right)$ release, which is important for the cow to show proper estrus. If concentrations of $\mathrm{P}_{4}$ are low, the dominant follicle might persist, which is often the case in dairy cows (Inskeep and Dailey, 2005). In a pregnant cow, maintaining high $\mathrm{P}_{4}$ is important to limit the release of prostaglandin F2 $\alpha$ (PGF2 $\alpha$ ), which causes luteolysis and embryonic mortality (Inskeep and Dailey, 2005). As feed intake increases a reduction in $\mathrm{P}_{4}$ is observed so as high producing cattle are eating more, concentrations of $\mathrm{P}_{4}$ are likely to decline post-breeding due to increased liver blood flow (Vasconcelos et al., 2003; Inskeep and Dailey, 2005). Thus, the metabolic status of the dairy cow influences pregnancy success.

The above criteria indicate conditions leading to subfertility in today's dairy herd. The overall reproductive health status of these cows has been overlooked for many generations and as a result $80-90 \%$ of oocytes are fertilized, but by day 45 only approximately $40 \%$ survived (Sreenan et al., 2001). Two critical time periods in embryonic development are thought to be days 5 to 8 and days 30 to 36. The embryonic development from days 5-8 consists of morula to blastocyst stage and during this time the embryo is transferred to the uterus (Inskeep and Dailey, 2005). The development of placentomes occurs on days 30 to 40, and the attachment of embryo is designated around day 30 (Inskeep and Dailey, 2005). If the embryo has the capacity to signal to its mother through release of IFN $\tau$ derived from the trophoblast (days 14-17) to maintain the pregnancy and can have successful attachment; the pregnancy is typically maintained (Inskeep and Dailey, 2005). Placing great emphasis on early postpartum cows and their resumption to cyclicity is important to decrease number of cows culled. The typical dairy cow is not being successfully bred back until past 100 days in milk (DIM). Reducing the NEB associated with the dairy herds today will likely allow for proper IGF-1 production in the liver and its transport to target tissues along with appropriate concentrations of $\mathrm{GH}$, allowing for cyclicity to resume and embryonic development to occur. If such things as cofactors (i.e. vitamin $\mathrm{B}_{12}$ or cobalt) supplementation can be used to decrease the duration of NEB, the cow might remain in the dairy herd by reaching cyclicity earlier postpartum and decreasing her calving intervals. This would 
decrease the cost to the dairy farmer due to increased milk yields and possessing the cows longer thus reducing the costs of heifer upbringing, as well as, decreasing the amount of dry off period before resumption of calving and lactation.

The stress of lactation may impose negative effects on the cow's metabolism, hematology, immune system, and reproductive function. The negative effects are likely from many factors that decrease overall health of the dairy cow, such as nutritional deficiencies, severe body weight loss, and improper liver function (overloaded due to increased lipolysis and lactation causing greater hepatic clearance of hormones). These negative effects are likely associated with decreased oocyte competence, in turn affecting the reproductive capacity of the cow through inadequate hormone signaling enabling embryonic death. The goal of this study was to determine whether factors such as BCS (categorized as lean, moderate, and overconditioned), parity, hematologic profiles, milk production, disease, and concentrations of Hp were indicators of reproductive success.

\section{INTRODUCTION}

The dairy cattle industry has changed dramatically over the past 30 years. The average milk yield in 1980 was $8,028 \mathrm{~kg}$ /year, whereas in 2012, dairy cows were producing an average of $12,342 \mathrm{~kg} /$ year (USDA, 2014). These changes are associated with genetic selection for milk quality and production causing a greater alteration in the animals' physiology and its ability to compensate for increasing lactation.

The lactating dairy cow experiences a NEB upon calving due to decreased DMI associated with the stress of calving and increased glucose expenditure by the mammary gland. The postpartum dairy cow is faced with low glucose availability, causing her to undergo various metabolic changes to overcome this deficit (stress). Low energy status stimulates the release of ACTH from anterior pituitary (Berg et al., 2001; Uchoa et al., 2014). The ACTH stimulates production of GC and also $\mathrm{GH}$, which allow for increased glucose availability via lipid mobilization and lipid and amino acid breakdown for energy (Butler, 2012; Berg et al., 2001; O’Connor et al., 2000; Uchoa et al., 2014).

Ketosis often occurs in cows with severe NEB and is highly correlated to slower resumption of reproductive function. When ketosis occurs, the LH pulse frequency is inadequate leading to a delay in ovulation time (Butler, 2012). A ketotic cow has less immune response associated with delayed uterine involution and proper cleanup postpartum via macrophages and neutrophils (Merck Animal Health, 2012). The immune suppression of dairy cattle decreases their ability to fight off infections and is associated with declined pregnancy success. A ketotic cow is more susceptible to diseases such as endometritis and retained placenta (Merck Animal Health, 2012). The fatty acid outcomes are important in understanding the cow's energy status and reproductive health. The accumulation of triacylglycerides leads to hepatocyte and mitochondrial damage (Wathes et al., 2013), as well as peripheral tissue damage and metabolic alterations due to increased oxidative stress within these tissues.

Polymorphonuclear neutrophils are the first line of defense during a pathogenic invasion; they are normally $25 \%$ of total leukocyte count (Paape et al., 2003). In the case of invasion and 
inflammation, an influx of neutrophils may be observed and in extreme cases, immature neutrophils will be released from the bone marrow known as a left shift (Jain, 1986; Paape et al., 2003). The neutrophilic response to foreign material is to eliminate it through oxidative burst activity (Paape et al., 2003; Hammon et al., 2006; Galvao, 2012). Cattle with increasing concentrations of NEFA appear to have reduced neutrophilic oxidative burst activity (Hammon et al., 2006).

Glucocorticoids increase concentrations of neutrophils, as well as reduce the synthesis of prostaglandins (O'Connor et al., 2000). The transition dairy cow undergoes an acute phase response during this stressful time period. Changes in the cow's physiology include but are not limited to inflammation, fever and suppression of appetite. The acute phase response is under the control of various cytokines, used for signaling that are often produced by macrophages (defense mechanism). The immune system begins to increase the release of cytokines such as TNF $\alpha$ causing an inflammatory response, insulin resistance (via phosphorylation of IRS-1), and stimulation of CRH from the hypothalamus (Beitz, 2014; Combs, 1998; Uchoa et al., 2014). When TNF $\alpha$ is secreted, an immune response is initiated, causing great amounts of glucose, amino acids, and adipose tissue to be used as energy sources (Beitz, 2014). The TNF $\alpha$ is associated with causing lipolysis, cellular apoptosis and necrosis (Beitz, 2014).

Release of CRH leads to the increased synthesis of cortisol and other glucocorticoids that reduce reproductive function (Squires, 2003; Berezi et al., 2005) while enhancing glucose production through gluconeogenesis and lipolysis of triglycerides. Cortisol is released during times of stress and low concentrations of glucocorticoids (Combs, 1998). Cortisol is responsible for metabolism of proteins, fats and carbohydrates via breaking down sugars from the body's storage reservoirs (triglycerides and glycogen) in times of low blood sugar (Combs, 1998). It plays a role in onset of lactation in addition to its relationship with glucose uptake in mammary tissue (Tucker, 2000). This is an important mechanism for a dairy cow during the last three weeks prepartum and first 100 days postpartum due to her inability to maintain sufficient glucose for lactation and body weight regulation as observed through monitoring BCS. Dairy cattle in high stress have increased glucocorticoids, which can lead to suppressed effects on IGF-1 despite increased GH secretion (O'Connor et al., 2000; Lucy, 2012). Glucocorticoids initiate gluconeogenesis, which also causes the GH and IGF-1 axis to become uncoupled loss of GHR1A and causes suppression of IGF-1 production within the liver (Lucy, 2012). IGF-1 is an important growth factor that acts as a negative feedback regulator for GH (Lucy, 2012). The functions of IGF-1 include cell proliferation and as an anti-apoptotic factor. A reduction of IGF1 concentrations is seen during a fasting state. If the GHR-1A is down regulated it causes the decrease in IGF-1 production. IGF-1 is important for gonadotropin responsiveness of ovarian follicles for maturation, as reviewed by Butler (2012).

The reduction in fertility of dairy cattle has been associated with genetic selection for milk yield rather than fertility. Khatib et al. (2009) found specific genotypes portraying antagonistic roles between the two traits. There is a negative correlation between milk production and conception rate to artificial insemination of lactating cows during high energy expenditure (Demetrio et al., 2007).

Epigenetics focuses on inheritance of divergent gene expression without altering the DNA sequence (Kropp et al., 2014). Each parent is a factor in determining the gene expression of the embryo and reduction in metabolic status decreases embryonic development (Demetrio et 
al., 2007; Ramalho-Santos et al., 2009; Kropp et al., 2014). Oocyte competence, fertilization, and ability to successfully divide through blastocyst stage are some of the many steps to successful embryonic development (Kropp et al., 2014).

For a successful attachment and pregnancy, the trophoblast of the conceptus has to be able to release IFN $\tau$ prior to attaching to the endometrium of the uterus. Attachment occurs when fetal cotyledons attach to maternal caruncles to form the epitheliochorial placenta (Bauersachs and Wolf, 2013). The IFN $\tau$ assists in maintaining the CL, which is responsible for the production of the pregnancy hormone, $\mathrm{P}_{4}$. In a non-pregnant cow, $\mathrm{P}_{4}$ primes the hypothalamus to respond to ovarian estrogen $\left(\mathrm{E}_{2}\right)$, which is important for the cow to show proper estrus. If $\mathrm{P}_{4}$ is low, it can lead to persistence of the dominant follicle, in lactating dairy cows (Inskeep and Dailey, 2005). In a pregnant cow, maintaining high $\mathrm{P}_{4}$ is important to prevent embryonic mortality (Inskeep and Dailey, 2005). It is important to note that as feed intake increases a reduction in $\mathrm{P}_{4}$ is observed due to increased liver blood flow associated with lactation (Vasconcelos et al., 2003). The above variables are influenced by the metabolic status of the dairy cow and; influencing pregnancy.

In this study, blood profiles were developed in lean, moderate, and over-conditioned cattle during the pre- and postpartum periods to determine if subsequent reproductive success was associated with changes in body condition score and health throughout as determined by veterinary diagnosis or hematological measures: hematocrit, white blood cell count, and Hp. Breeding method, parity, and milk production also were examined for association with reproductive success. Reproductive success was considered as confirmed pregnancy, while failure was either no conception to first artificial insemination or no insemination by decision of herd manager or being sold or dying.

\section{MATERIALS AND METHODS}

The experiment was conducted between August 2013 and May 2014 on a commercial dairy farm ${ }^{1}$ that milks three $(3 x)$ times daily at 0600, 1400, and 2200 hours, approximately 700 Holstein Friesian cows maintained in free stall barns yearly. The cattle were dried off for 60 days before expected calving. At the start date in August, the 72 cows that were approaching 45 days until expected parturition were enrolled in the experiment without any consideration for the animal's milking ability, lactation number, age, etc. Animals in the dry period of their 1 to 7 lactation $(\underline{x}=2.5)$ and were 2 to 8 years of age $(\underline{x}=3.6)$ at the onset of the experiment.

Blood samples were taken with a 20 gauge needle by venipuncture of the caudal tail vein before morning feeding (0700) beginning 45 days prior to expected calving date $(-45 \mathrm{~d})$ and then at $+1,+4$, and +20 to 26 days after calving for each cow. Blood samples were taken (0500-0800) after morning milking on 26-32d after the first artificial insemination. Samples were collected into EDTA vacutainer tubes and placed on ice. Hematocrits were determined, and plasma was harvested after centrifugation and snap-frozen in liquid nitrogen for transportation and then storage at $-80^{\circ} \mathrm{C}$ in the laboratory.

\footnotetext{
${ }^{1}$ DoVan Farm (Berlin, Pennsylvania; $708 \mathrm{~m}$ above sea level; $39^{\circ} 55^{\prime} 12^{\prime \prime} \mathrm{N}, 78^{\circ} 57^{\prime} 0^{\prime \prime} \mathrm{S}$ )
} 
Body condition score (BCS) was assessed by two investigators and averaged using a five point scale (Ferguson et al., 1994) at $-45,-30,-15,-7,1,4,21,35$, and $49 \mathrm{~d}$. At -30 d, cows were assigned into categories of lean (BCS $\leq 3.25$ ), moderate (BCS $>3.25-3.75$ ) or over-conditioned $(\mathrm{BCS} \geq 3.75)$. The BCS at 26 to $32 \mathrm{~d}$ after insemination was determined by one investigator.

\section{a. Milk Production and Health Summaries}

Milk data were collected from PCDart (DRMS, Raleigh, NC) for each cow through 60 DIM. The herd veterinarian performed routine examination of cows, and the health status (Table 1) of each cow was recorded from $-45 \mathrm{~d}$ through the cow's first pregnancy examination (PC) or the time that she was culled from the herd. Whole blood cell counts were performed using a Beckman Coulter Counter Z series (Hialeah, FL). Blood smears were used to determine differential white blood cell counts at each time point. A bovine Hp assay (Life Diagnostics, West Chester, PA) was performed on samples from 64 cows at the routine pre-breeding examination (20-26 d).

\begin{tabular}{|l|c|}
\hline \multicolumn{1}{|c|}{ DISEASES } & TOTALS \\
\hline \multicolumn{1}{|c|}{ Metabolic } & $\mathbf{2 6}$ \\
\hline Milk Fever & 4 \\
\hline Ketosis & 3 \\
\hline Digestive & 15 \\
\hline Left Displaced Abomasum & 3 \\
\hline Diarrhea & 1 \\
\hline \multicolumn{1}{|c|}{ Reproductive } & $\mathbf{2 7}$ \\
\hline Abortion & 3 \\
\hline Retained Placenta & 9 \\
\hline Metritis & 13 \\
\hline Calving Difficulty & 1 \\
\hline Twin Birth & 1 \\
\hline \multicolumn{1}{|c|}{ Mammary } & $\mathbf{1 5}$ \\
\hline Right Rear Quarter & 1 \\
\hline 2+ Quarters & 14 \\
\hline \multicolumn{1}{|c|}{ Structural } & $\mathbf{1}$ \\
\hline Hoof Rot & 1 \\
\hline Infectious & $\mathbf{2}$ \\
\hline Pneuomonia & 1 \\
\hline Salmonella & $\mathbf{1}$ \\
\hline Total Disease Occurrence & $\mathbf{7 1}$ \\
\hline Culled or Deceased & $\mathbf{9}$ \\
\hline
\end{tabular}

Table 1. Disease frequency by categorized health disorders over all time points. 


\section{b. Feed Sample Analysis}

Feed samples were collected for near infrared (NIR) analysis from the recently calved (fresh) and close-up groups. The feed samples were analyzed using NIR 1 (Cumberland Valley Analytical Services, Hagerstown, MD; Table 2) ${ }^{2}$. The cobalt supplementation used during this study for all diet groups was $1.64 \mathrm{ppm}$.

\begin{tabular}{|c|c|c|c|c|c|c|c|c|c|c|}
\hline Diet & Dry Matter & Crude Protein (\%DM) & Adjusted Protein (\%DM) & ADF (\%DM) & Crude Fat (\%DM) & Ash (\%DM) & NEl & NEm & NFC & NSC \\
\hline Far-Off & 49.1 & 11.55 & 10.7375 & 32.7 & 3.22375 & 7.33375 & 0.65375 & 0.64125 & 30.4 & 19.6625 \\
\hline Close-Up & 49.01666667 & 12.3 & 11.43333333 & 31.58333333 & 3.083333333 & 7.36833333 & 0.66333 & 0.65333 & 36.0167 & 20.7 \\
\hline Lactating & 47.38333333 & 16.45 & 16.45 & 21.36666667 & 4.356666667 & 7.41666667 & 0.75667 & 0.775 & 41.5333 & 30.4667 \\
\hline
\end{tabular}

Table 2. Feed sample analysis for far-off, close-up, and lactating groups.

\section{c. Reproductive Measurements}

The cattle were palpated per rectum routinely by the veterinarian ${ }^{3}$ for presence of ovarian follicles or CL and monitored for estrus. Records were kept for all reproductive measures and synchronization of ovulation (Ovsynch) protocol used for breeding. Each cow had her uterus "raked" manually and received an injection of a prostaglandin F2-alpha (PGF2- $\alpha$ ) analogue (Estrumate $\odot$ Intervet/Merck Animal Health Summit, NJ) at (20-26 d) after calving. A presynchronization (Pre-synch) process began on d 35 and was followed by the Ovsynch program beginning on $\mathrm{d} 49$. One technician used tail chalk as an estrous detection aid and routinely checked the herd four times daily for external signs of estrus. The same technician artificially inseminated the cattle $12 \mathrm{~h}$ after they were first detected in estrus or used timed insemination (48 hours after the second Estrumate injection) if the animal had not shown estrus. Pregnancy diagnosis was made ultrasonically by the herd veterinarian at 26 to $32 \mathrm{~d}$ post-insemination. For statistical purposes the conception rate was calculated first. The pregnancy success was then analyzed using all cows present at the prepartum period. This included cows that may have been culled or deceased after parturition and were recorded as non-pregnant for analysis purposes.

\section{d. Statistical Analyses}

For analysis, cattle were grouped by BCS (range 2.375 to 4.5 ) at $-30 \mathrm{~d}$ prepartum into lean $(2.375$ to $\leq 3.25)$, moderate $(>3.25$ to 3.75$)$, and over-conditioned $(\geq 3.75$ to 4.25$)$ categories. The health status was amalgamated into metabolic, reproductive, hoof/limb or healthy categories at four time periods: prepartum $(-45 \mathrm{~d})$ to parturition, early postpartum (d 0 to 10$)$, pre-breeding and post-breeding.

Time classes were used to determine if there were time points associated with a cow's reproductive success (reproductively fit and became pregnant from first artificial insemination). A "Proc mixed autoregressive correlation matrix" using repeated measure ANOVA was used to compare BCS category, day and BCS category by day interaction. A Chi-Square contingency analysis was performed on pregnancy success including culled/deceased (culled or deceased were classified as inadequately meeting requirements for fertility therefore, identified as non-

\footnotetext{
${ }^{2}$ Nutrition consulting was provided through Renaissance Nutrition Roaring Springs, PA.

${ }^{3}$ Herd veterinary services were through White Oak Veterinary Clinic Berlin, PA by the same experienced veterinarian.
} 
pregnant cows) for effects of BCS category and first breeding by BCS category. The second breeding DIM was not normally distributed, even after log transformation, so the nonparametric Kruskal- Wallis test was used. A "Proc mixed repeated measures ANOVA" was used to analyze hematocrit for effects of time and BCS. Haptoglobin was analyzed for bivariate fit of $\log _{(\text {base } 10)}$ transformation of $\mathrm{Hp}$ by hematocrit and by milk average (d 20 -26) for pre-breeding. An ANOVA of log transformation of Hp by BCS category and by time (pre-breeding) was performed. A logistic fit of pregnancy by log transformation of $\mathrm{Hp}$ and a contingency analysis of pregnancy by $\mathrm{Hp}$ and category were analyzed. A binary logit using log of odds ratio was used for high $\mathrm{Hp}$ and high milk interaction. An autoregressive repeated measure ANOVA was used to analyze white blood cells by time and category. The least square means were placed on log scale and values that equaled zero used the formula as follows: $\ln *[($ monocytes/1120556.1 $)+0.2]$, $\ln *[($ segmented neutrophils/1228374.4) +0.2$]$, and $\ln *[($ eosinophils/540963.4) +0.2$]$. Basophils were not normally distributed and excluded from the analysis.

\section{RESULTS}

\section{a. Body Condition Score}

The BCS varied with main effects of category and day, as well as a day by category interaction. Over-conditioned cows maintained a higher BCS throughout; all categories lost BCS from prepartum ( $\mathrm{p}<0.0001)$; and the interaction among the cows occurred due to each category increasing BCS at the post-conception time (Figure 1). There were significant changes in pattern of body condition between pre and postpartum time points for each category ( $p=0.0001$; Figure 1 ), as well as within each category ( $\mathrm{p}=0.001$; Figure 2$)$. When comparing $\mathrm{d}-30$ to pre-breeding time point (Figure 2), the greatest loss in BCS for lean group was 0.9, whereas in overconditioned cows, the greatest BCS loss was 1.3 on the (1-5 scale using 0.25 increments), indicating the amount of loss varied among categories. Cattle body condition losses were highest in the over-conditioned when compared to the other two categories from d -30 to pregnancy check, mean $95 \mathrm{~d}$ postpartum $(\mathrm{p}=0.0001)$. All cows were losing BCS at $\mathrm{d} 4$ and therefore, no significance was found at this time point. There were significant differences in BCS loss between over-conditioned cows versus lean and moderate cows ( $\mathrm{p}$-value $=0.001$ ) from $\mathrm{d}-30$ to $\mathrm{d} 4$ and to d 21 . 


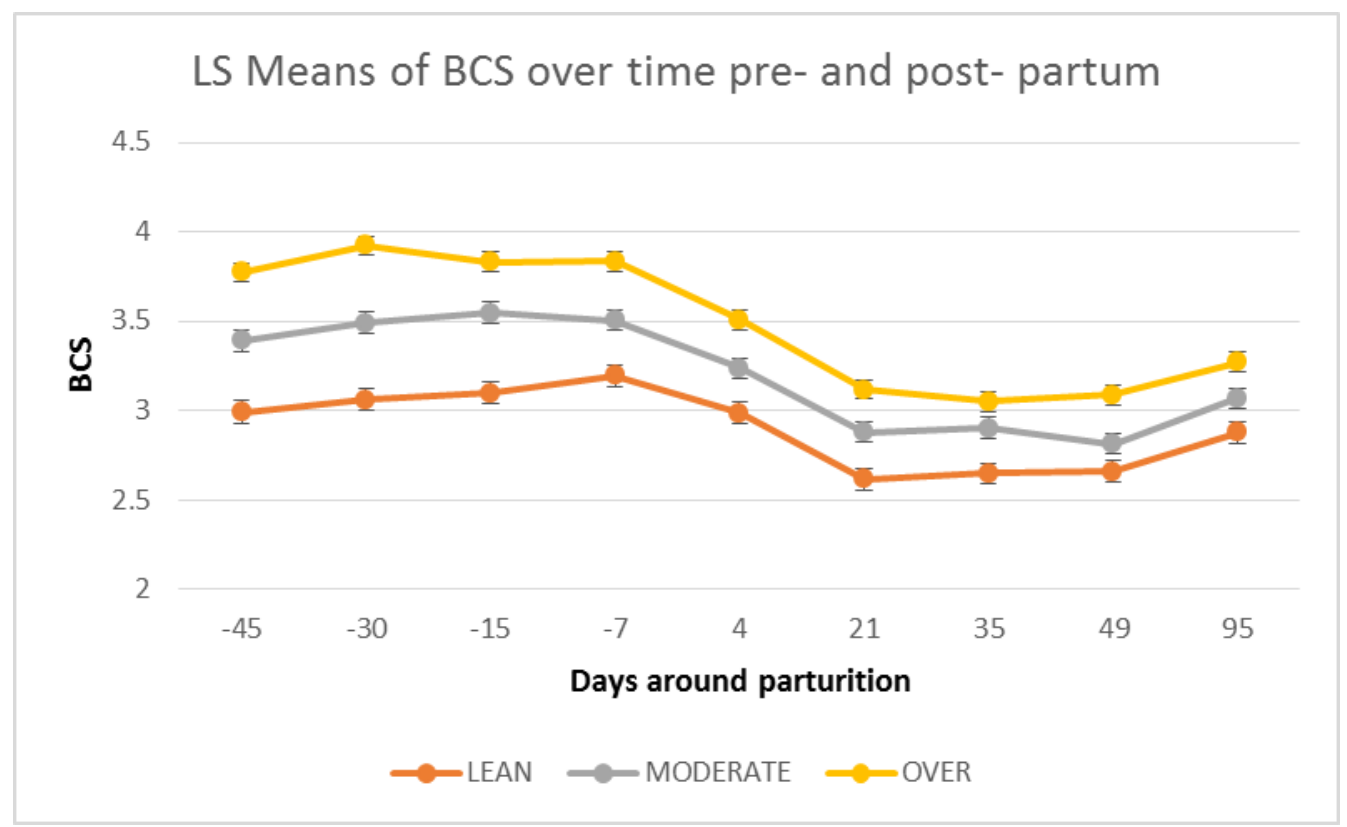

Figure 1. Least square means body condition score (BCS) means $( \pm \mathrm{SE})$ at various time-points for cows categorized as lean, moderate, or over-conditioned 45 days prepartum through pregnancy

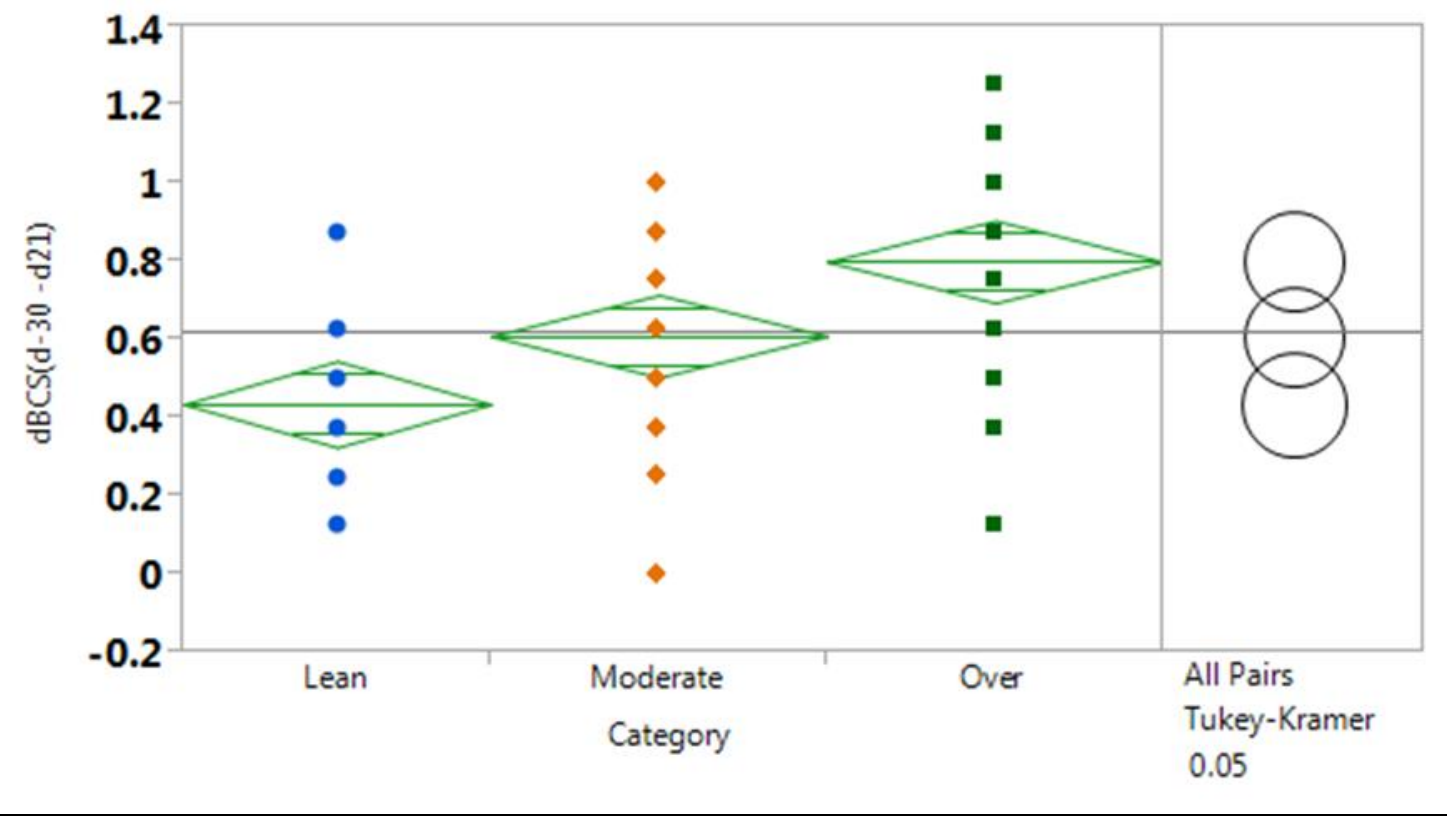

Figure 2. Comparison of BCS loss between d -30 prepartum and d 21 to 26 (pre-breed) postpartum within lean, moderate, and over-conditioned cows $(\mathrm{p}=0.0001)$.

\section{b. Health Status}

Of the 72 cows enrolled in the study, one cow was excluded due to insufficient samples. For statistical purposes the health disorders were placed into six categories: metabolic, reproductive, mammary, structural, infection, and deceased or culled (Table 1). Documented 
diseases occurred in 42 cows over the length of the study. Of the 71 incidences of diseases, 15 cows had 2 to 9 diseases at one or more time points including disease reoccurrences or new disease diagnoses. Of the cows with metabolic diseases such as ketosis, $2 / 3$ were overconditioned and $1 / 3$ were lean. The distribution of cattle with digestive disturbances were 8/15 over-conditioned, 2/15 moderate, and 5/15 lean. Because of the low frequency for a specific disease, cows were classified as diseased or healthy for further analyses. Prevalence of disease at any time (lean $28.6 \%$, moderate $33.3 \%$, and over-conditioned $38.1 \%$ ) was not associated with prepartum BCS. The distribution of diseases over time showed that prepartum cattle were relatively healthy (10\% diseased) and that during the first $10 \mathrm{~d}$ postpartum disease frequency increased to $30 \%$ at which it remained for the pre-breeding (31\%) and post-breeding (31\%) periods. Nine cows distributed uniformly across all BCS categories either were culled or died. There was an effect of disease on pregnancy success during the first $10 \mathrm{~d}$ following parturition (Figure 3) and at the pre-breeding time (20 to $26 \mathrm{~d}$; Figure 4).

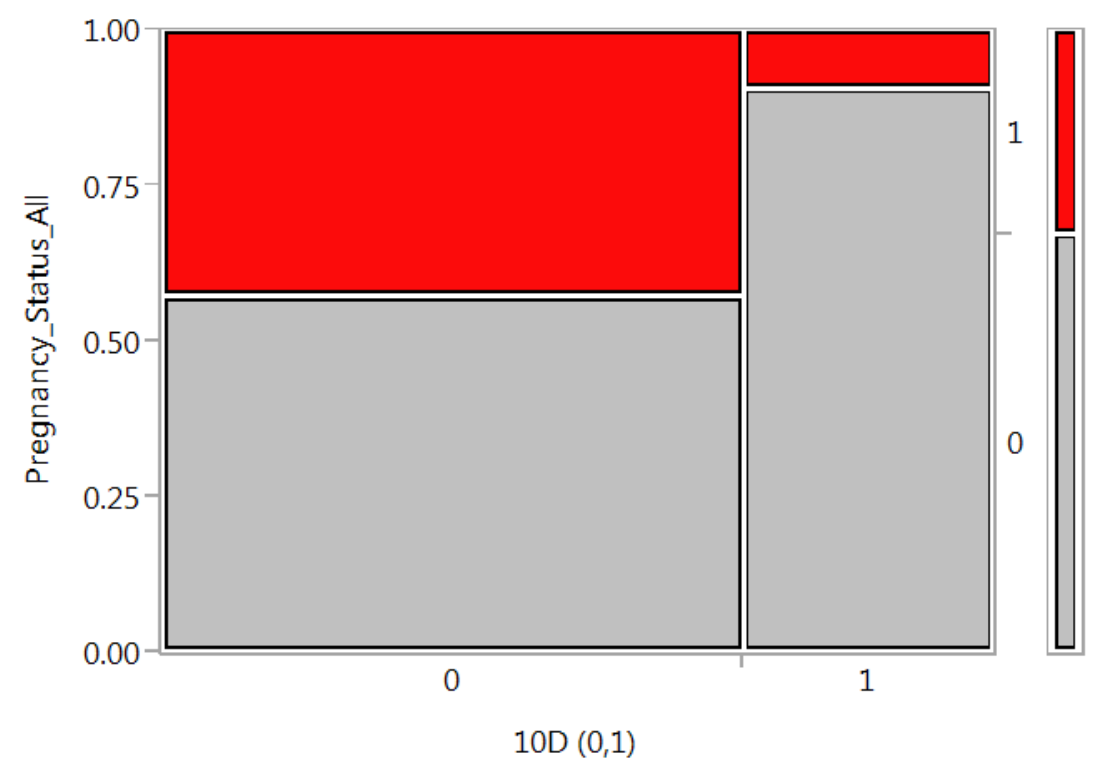

Figure 3. Mosaic plot of contingency analysis of pregnancy status by first $10 \mathrm{D}$ following parturition all cows included for disease prevalence $(0=$ no disease, $1=$ diseased $) p$-value $=0.006$ 


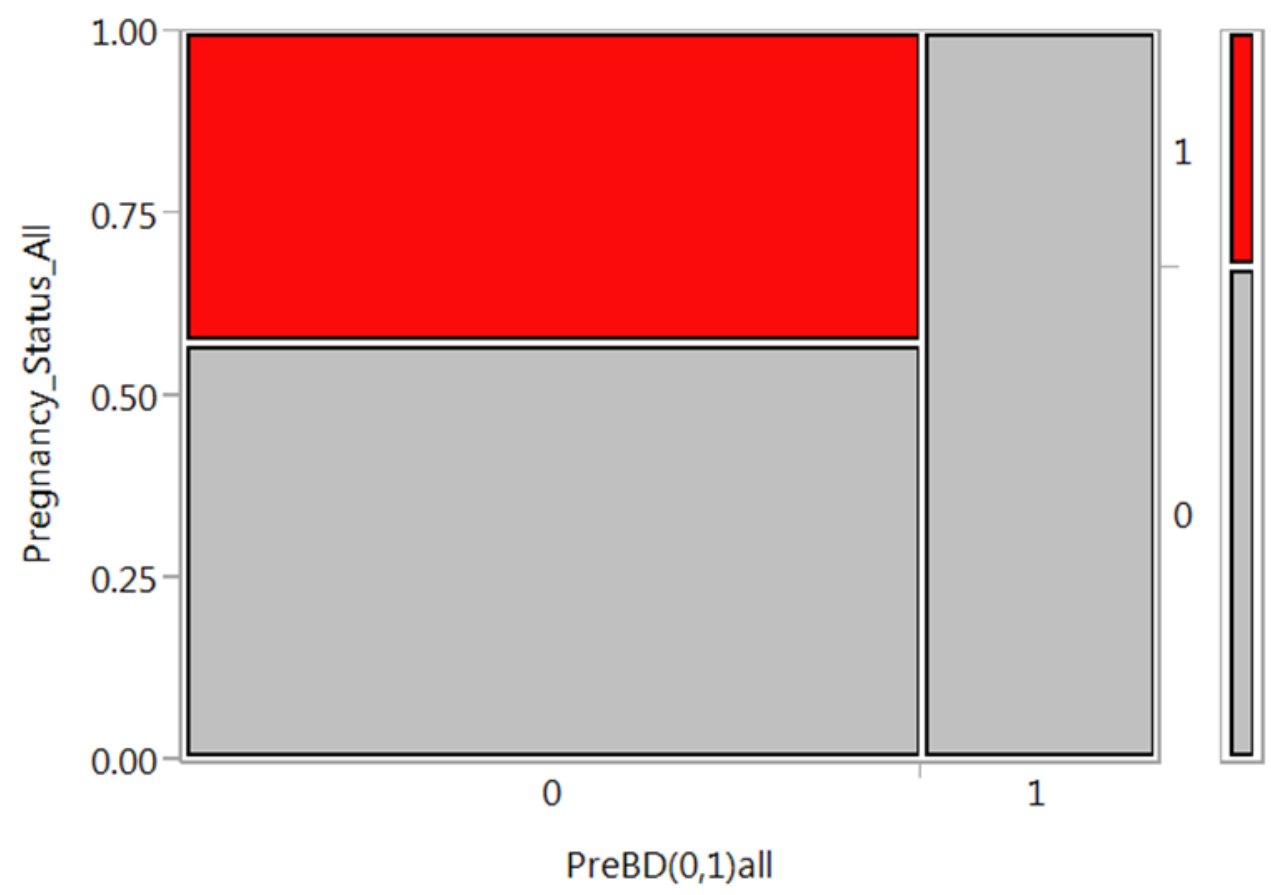

Figure 4. Mosaic plot of contingency analysis of pregnancy status by pre-breeding time (20 to 26 d) all cows included for disease prevalence $(0=$ no disease, $1=$ diseased $)(p=<0.0001)$

When looking at effects of parity overall health and disease, risk of disease increased $(\mathrm{p}=$ 0.01 ) Figure 5) as number of lactations increased by lactation 5 all cows developed at least one disease. Parity affected disease prevalence $(\mathrm{p}=0.01)$ at $10 \mathrm{~d}$ postpartum but not prepartum. The pre-breeding time showed a trend when all cattle (culled and deceased) were used in analysis such that number, as of lactations increased the incidences of diseases tended to increase. When all cows were included in the analysis, frequency of disease occurring post-breeding was related to increasing parity $(\mathrm{p}=0.006)$. 


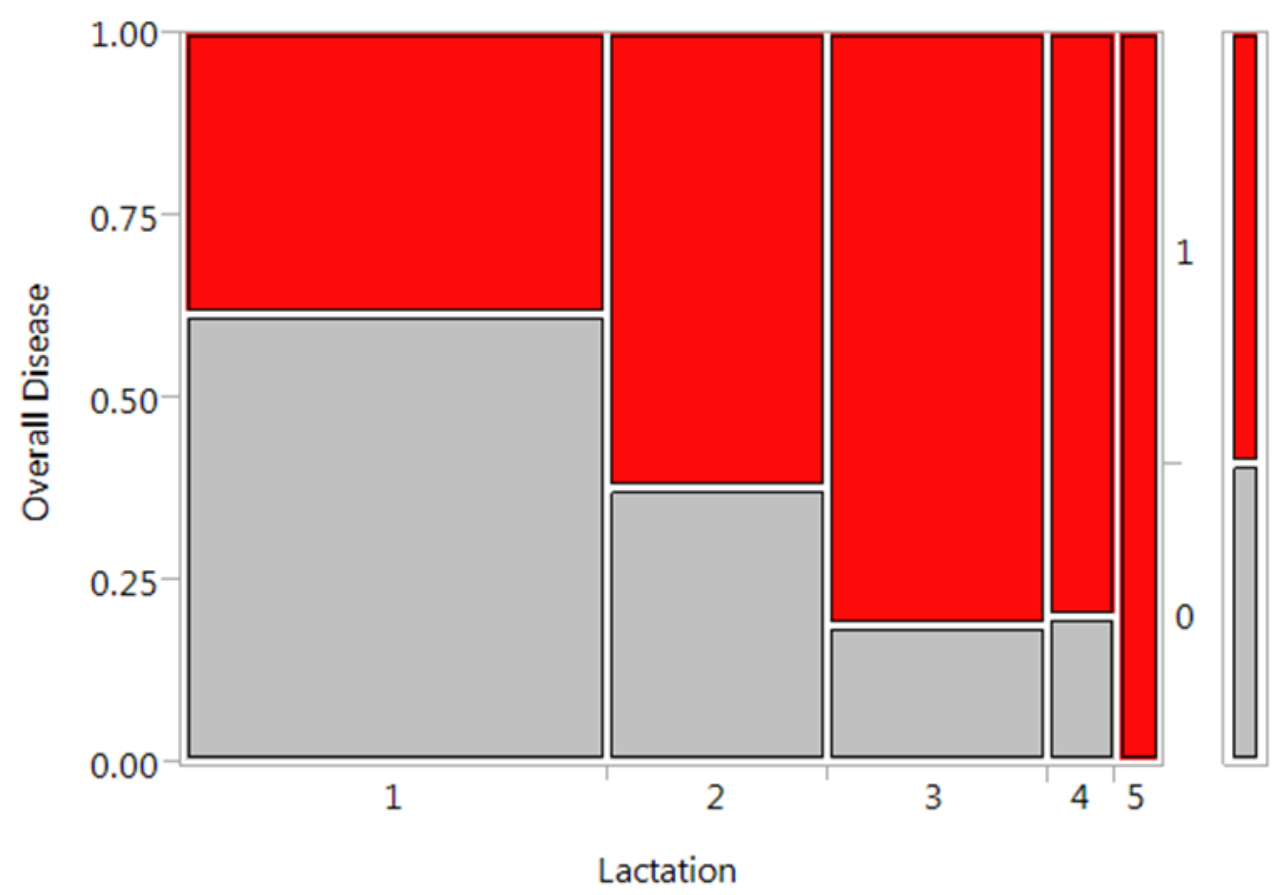

Figure 5. Contingency analysis of overall frequency of occurrences of disease $(0=$ healthy, $1=$ diseased) at any time as affected by parity $\left(\mathrm{X}^{2}=0.0111 \mathrm{p}=0.01\right)$.

Hematocrit differed with day $(\mathrm{p}=0.0001)$ but was not affected significantly by BCS or the interaction of BCS with time. The hematocrit declined in all groups to a nadir at d 20-26 and then increased (Figure 6). 


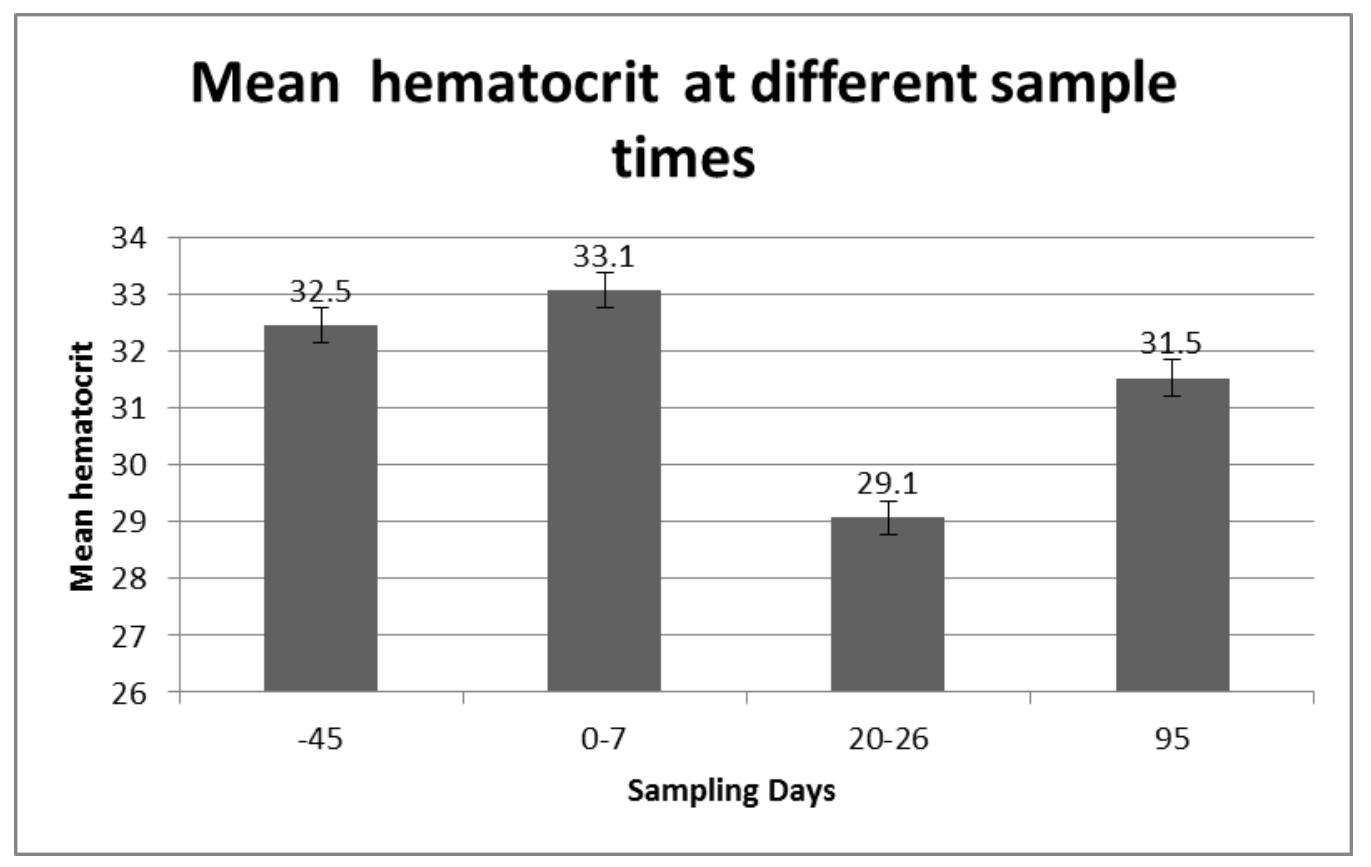

Figure 6. Hematocrits at prepartum (d -45), early postpartum (d 0 to 7), pre-breeding (d 20 to 26 ), and pregnancy check ( 26 to 32 days after insemination, mean $=95$ days postpartum $)(\mathrm{p}=$ $0.0001)$.

The leukocyte counts had a main effect of day for monocytes $(\mathrm{p}=0.0001)$, banded neutrophils $(\mathrm{p}=0.007)$, segmented neutrophils $(\mathrm{p}=0.0007)$, total neutrophils $(\mathrm{p}=0.001)$, and eosinophils $(\mathrm{p}=0.0001)$, but not for counts of lymphocytes. There was no significant difference in BCS category or BCS category by day (Figure 7); therefore, the mean for each group was calculated for each leukocyte at the different time points (Figure 8 and Table 3 ). Excluding the lymphocytes, numbers of neutrophils and monocytes increased while numbers of eosinophils decreased from prepartum to d 0 to 7 . Numbers of total neutrophils recovered by d 20 to 26; numbers of monocytes returned to normal by d 26- 32 PC; while numbers of eosinophils remained decreased throughout. 


\section{Leukocyte counts by cattle category and time}

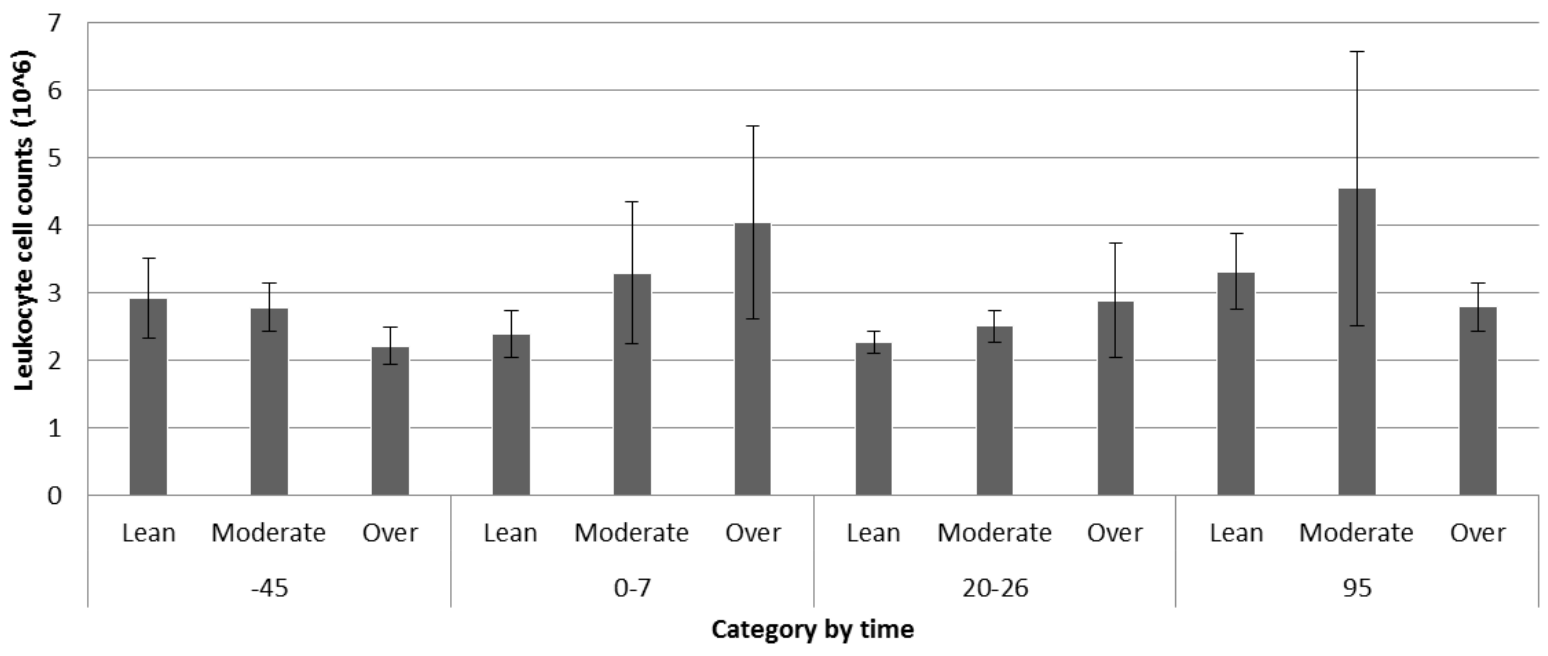

Figure 7. Repeated measures ANOVA of mean leukocyte cell counts $\left(10^{\wedge}{ }^{6}\right.$ per $\left.\mathrm{mL}\right)$ by BCS category (lean, moderate, and over-conditioned) for prepartum (d - 45), early postpartum (d 0 to 7), pre-breed (d 20 to 26), and pregnancy check ( 26 to $32 \mathrm{~d}$ after insemination, mean $=95 \mathrm{~d}$ postpartum) (no significance, $\mathrm{p}=0.7043$ ).

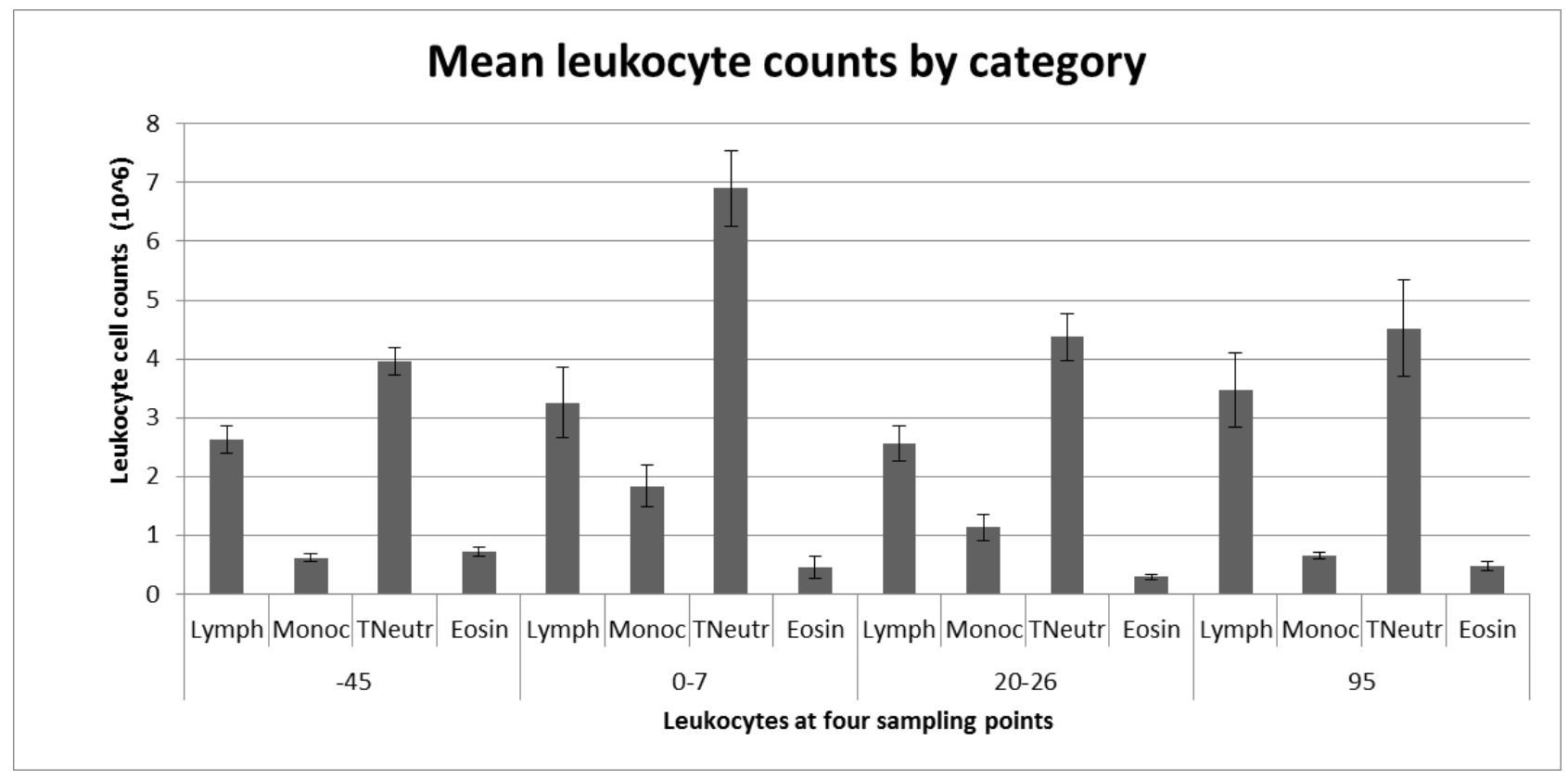

Figure 8. Repeated measures ANOVA of mean leukocyte counts $\left(10^{\wedge}{ }^{6}\right.$ per $\left.\mathrm{mL}\right)$ for prepartum $(\mathrm{d}$ 45), early postpartum (d 0 to 7 ), pre-breeding (d 20 to 26), and pregnancy check ( 26 to $32 \mathrm{~d}$ after insemination, mean $=95 \mathrm{~d}$ postpartum) $(\mathrm{p}$-values displayed in Table 3$)$. 


\begin{tabular}{|c|c|c|c|c|}
\hline & \multicolumn{4}{|c|}{ P-Values } \\
\hline Time Point & Lymphocytes & Monocytes & Total Neutrophils & Eosinophils \\
\hline 1 vs 2 & 0.9 & $<0.0001$ & 0.0005 & $<0.0001$ \\
\hline 1 vs 3 & 1 & 0.004 & 0.8 & $<0.0001$ \\
\hline 1 vs 4 & 0.4 & 0.7 & 0.6 & 0.04 \\
\hline 2 vs 3 & 0.8 & 0.05 & 0.001 & 0.5 \\
\hline 2 vs 4 & 0.1 & $<0.0001$ & 0.006 & 0.002 \\
\hline 3 vs 4 & 0.4 & 0.02 & 0.8 & 0.04 \\
\hline
\end{tabular}

Table 3. Tukey-Kramer analysis of differences of least square means p-values for the differing time points $[1=$ prepartum $(\mathrm{d}-45), 2=$ early postpartum (d 0 to 7$), 3=$ pre-breed (d 20 to 26), and $4=$ pregnancy check (26 to 32 post insemination)].

Haptoglobin analysis included 64 cows at the pre-breeding period (d 20 to 26). The log concentration of Hp was affected by milk average during pre-breeding ( $p=0.01$; Figure 9$)$ but not hematocrit or BCS category.

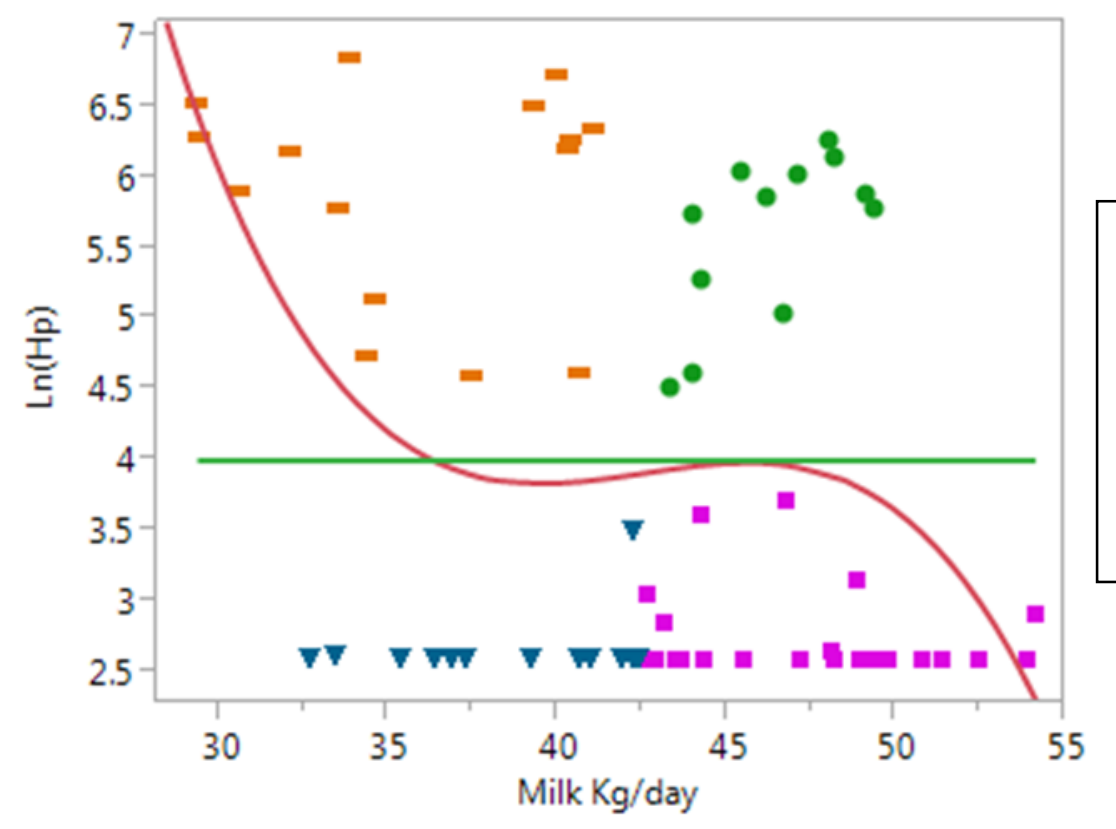

Orange rectangles= high $\mathrm{Hp} /$ low milk

Green circles $=$ high $\mathrm{Hp} / \mathrm{high}$ milk

Blue triangles= low $\mathrm{Hp} /$ low milk

Purple squares= low Hp/high milk

- Polynomial Fit Degree=3

- Fit Mean

Figure 9. Polynomial Fit (^3) $\log$ of $\mathrm{Hp}$ on d 20 to 26 by milk (kg/day) (The different shapes represent different quadrants $(\mathrm{p}=0.01)$. Mean of $\operatorname{lnHp}$ is 3.9 and mean milk is $42.67 \mathrm{~kg} / \mathrm{day}$.

\section{c. Pregnancy}

The mean day for first insemination was 69 DIM and was not affected by BCS category. The second breeding time for cattle that did not conceive to first artificial insemination was not affected by BCS category and was not normally distributed showing a division into two groups of cattle being bred a second time on average at 77 and 115 DIM (Figure 10). The method of 
breeding was classified as after heat detection (including any of the following indices veterinarian, standing, riding, mucus, OvSynch with signs, nervous-etc., drop in milk production, and chalk rub) or OvSynch without signs of heat. Although not significantly different, a 10 percentage point increase in pregnancies occurred in cows showing estrus.

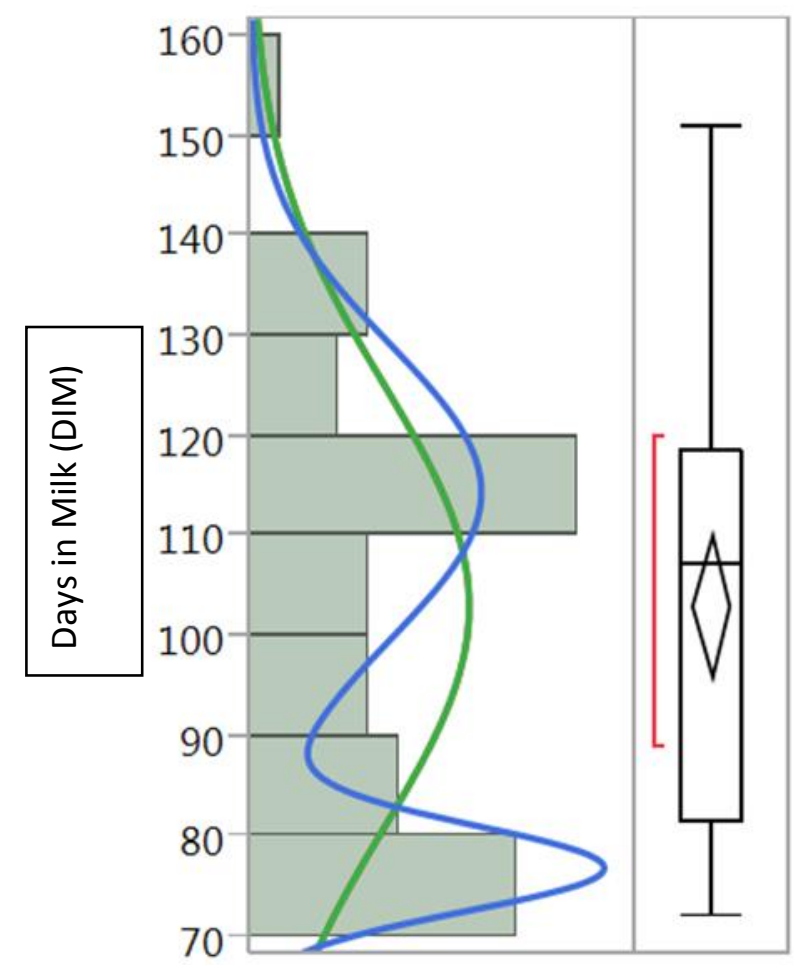

Figure 10. Distributions for second breeding DIM analysis using a nonparametric method (Kruskal-Wallis test).

The pregnancy status was analyzed for 71 cows (including culled/ deceased classified as not pregnant). The conception rate was 35\% (23/65) for the cows that were presented for breeding and pregnancy rate of $36.6 \%$ (26/71); however, 3 aborted between 32 to $46 \mathrm{~d}$ postinsemination, which is approximately a $9 \%$ loss, and those were recorded as failures $(23 / 71=$ $32.4 \%)$. Neither BCS nor hematocrit at any time point significantly affected pregnancy status. The contingency analysis of pregnancy (all cows) by group in milk and contingency analysis of pregnancy of all cows by BCS group and by Hp (above or below average) and level of milk production (above or below average) was significant $(\mathrm{p}=0.0003$, Figure 11). Relative rankings for pregnancy rates were high $\mathrm{Hp} /$ high milk $(66.67 \%)>$ lowHp/ low milk $(38.46 \%)>$ low $\mathrm{Hp} /$ high milk (25\%)> high $\mathrm{Hp} /$ low milk (6.67\%). The odds ratio was analyzed for the high haptoglobin/high milk and found that dairy cattle with both variables at pre-breeding are 52 times more likely to be pregnant to first artificial insemination. 


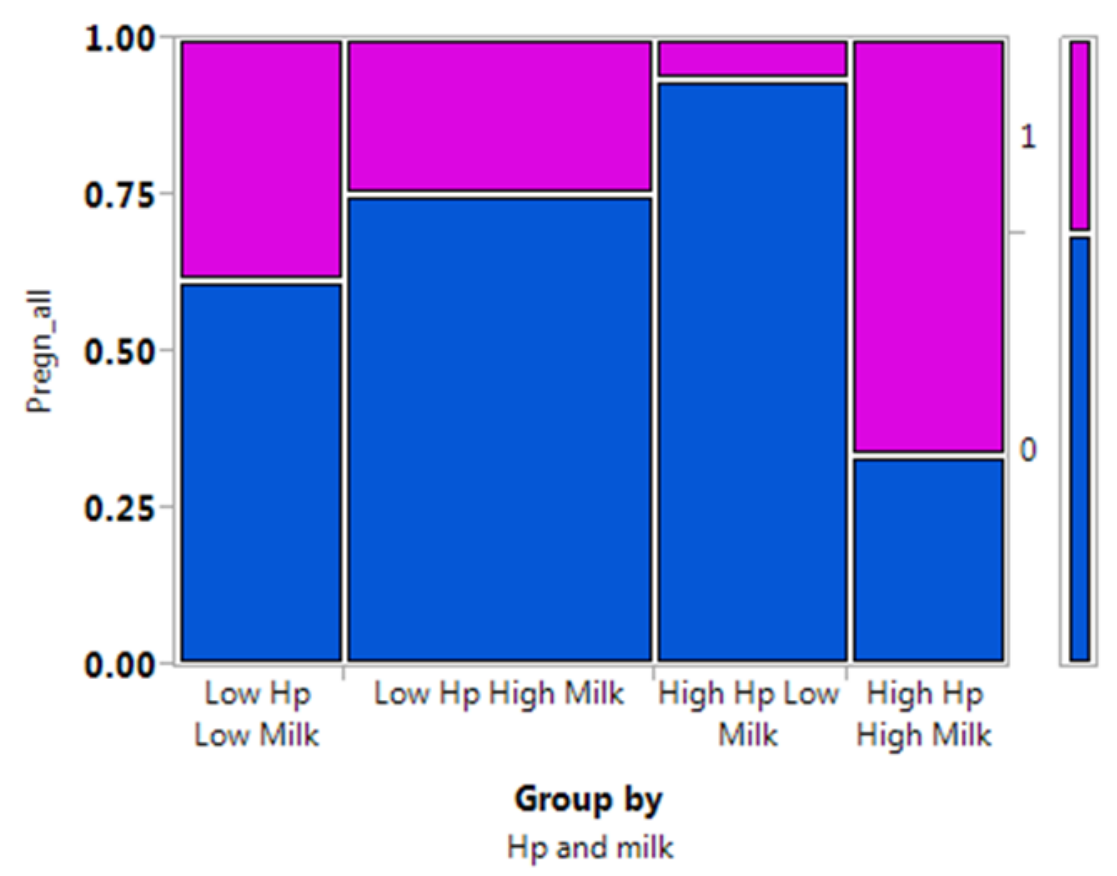

Figure 11. Contingency analysis of pregnancy percentage by concentrations of haptoglobin and average milk production ( 20 to $26 ; \mathrm{p}=0.0003$ ).

\section{DISCUSSION}

The study was performed on a commercial dairy that focuses on good management practices. The importance of this kind of study is that the data may be related more easily to other dairy farms in the United States than data from institutional research herds. The design of the study aimed to minimize unnecessary animal handling or stress. All cattle were treated the same and received the same ration and water. Blood sampling often was done in free stalls without further handling. Diseases were documented, and standard treatments were implemented.

Prepartum BCS had no effect on predicting pregnancy success. This finding is contradictory to Cardeso et al. (2013) who observed thin versus fat cows at -4 weeks prepartum had a longer interval to pregnancy. The relative changes in BCS also had no association with reproductive success. In contrast, Domecq et al. (1997) found that conception rate was reduced when cattle lose 0.4 unit of BCS after parturition, and Tamadon et al. (2011) found cows losing $\geq 0.5$ unit BCS at third week postpartum showed CL activity later than those cows losing less BCS during the same interval. In the current study cows were showing signs of ovulation (clear membrane discharge and standing estrus) at 20 to 26 days postpartum. Because BCS loss did not have an effect and the cows were showing cyclicity, the dairy either had a better nutritional plan or the cattle likely were less stressed than in other studies. The BCS losses were greater in the over-conditioned cattle, but, with respect to fat deposition, over-conditioned cattle would be more apt to remove adipose tissue from reserves.

There was no change in BCS from d 21 to 49 postpartum. This indicates no gain in fat deposition and only maintenance of body condition at this time (i.e. NEB continues through this 
time). The BCS losses began at d 4 and were maintained from d 21 to 49; thus the total mixed ration (TMR) was adequate for maintaining condition, but did not allow for gain during high lactation. At this time the cow would be described as in NEB. Liver function would be increasing to provide for gluconeogenesis and fat catabolism, so there would be concern for development of metabolic diseases. Glucose would be lowered further emphasizing the importance of having a TMR with high energy composition and sufficient mineral mixtures to decrease complications associated with high ruminal flow (decreased absorption of minerals and antioxidants).

The cow's ability to utilize the TMR components was important to assist her in remaining healthy. The TMR ration contained a higher percentage of cobalt, the mineral required for vitamin $\mathrm{B}_{12}$ synthesis within the rumen, than required. The implications of adding a mineral that does not show a high risk of toxicity in greater amounts than the NRC recommendations may have value to the herd. Catabolism of fats into acetyl Co-A and propionyl CoA (main fatty acid used in ruminants) is one of the key events during NEB. Vitamin $\mathrm{B}_{12}$ is associated directly with converting propionate to succinate, which then goes into the Krebs cycle for energy production (Berg et al., 2001). This is just one instance of the importance in properly balancing the TMR for the lactating dairy cow. Rations should include the proper mineral supplementation and energy components to maximize production and to minimize depletion of the body reserves, which causes insulin resistance due to increased lipolysis and the metabolic diseases associated with it (milk fever, ketosis, fatty liver). Low energy availability reduces ovarian activity via insufficient IGF-1 being present in reproductive organs (Butler, 2012). Tamodon et al. (2011) found lower IGF-1 in cows losing BCS. The effects of increased lipid accumulation and ketone formation reduce release of LH because GnRH secretion is inhibited when the cow has high concentrations of glucocorticoids. Thus, the gonads would not function adequately (Butler, 2012; O'Connor et al., 2000; Wathes et al., 2013).

Cows were either completely healthy or developed some form of disease (clinical or subclinical) after parturition. Diseases affected pregnancy status if the disease occurred during the first 10 days following parturition through the pre-breeding period, when no cows with a disease became pregnant by $95 \mathrm{~d}$. The diseases that developed after breeding did not affect the pregnancy status, which is consistent with a study performed on effects of mastitis on reproduction in Jersey cows (Barker et al., 1998) in which they found no effect of mastitis after a confirmed pregnancy on reproductive performance. This result indicates that the conceptus is able to maintain pregnancy once it has attached to the endometrium. Likely, some cows conceived and then lost the embryo and were never diagnosed as pregnant. However, embryonic loss prior to day 26 to 32 post breeding could not be estimated in this study. The three total losses in this study were based on later abortions (3/71 or $\sim 9 \%$ loss). The later the embryonic loss the higher the economic loss due to increased intervals to re-breeding.

Intervals to second breeding were not normally distributed. The separation of second breeding DIM into two groups involved 41 cows bred and not diagnosed as pregnant. According to PCDart, the DoVan farm had a heat detection of $72 \%$, a pregnancy rate of $34 \%$, and a calving interval of 394 days. Thus the AI technician was not missing heats too often; instead embryonic death may have occurred and heat had not been detected by the time of palpation ( 26 to $32 \mathrm{~d}$ post-insemination in the group with a mean of 115 DIM (46 d after first insemination).The method of breeding using OvSynch ${ }^{\circledR}$ may explain the detected estruses at 77 DIM, an average of $8 \mathrm{~d}$ after breeding. Some of the early estruses may have occurred within a few days after timed 
insemination, because the cows had not ovulated in response to the $\mathrm{GnRH}$, but ovulated naturally a few days later. The OvSynch protocol consists of injecting exogenous GnRH, a hormone typically secreted by the hypothalamus that is responsible for the LH surge. Estrogen is normally responsible for triggering that surge and for setting up $\mathrm{P}_{4}$ receptors in preparation for increasing $\mathrm{P}_{4}$ concentrations from the CL to set normal timing of the luteal phase. If the exogenous $\mathrm{GnRH}$ is given before luteal regression is complete and $\mathrm{P}_{4}$ in a cow is too high, the uterus is exposed to minimal $\mathrm{E}_{2}$, and there may be too few $\mathrm{P}_{4}$ receptors in the uterus, so that secretion of PGF $2 \alpha$ occurs too early, regressing the new CL and causing embryo loss (Inskeep, 2004). Proper timing and sequence of hormone secretions is essential for the optimal embryo development and maturity. Still a third, but less likely alternative for a short interval, would be lack of regression of the previous CL, in which case any newly formed CL would regress along with the original CL (Inskeep et al., 1963).

It is important that $\mathrm{GnRH}$ be given at the proper time relative to follicular development in the cow, otherwise it may cause ovulation of an immature oocyte, which can lead to either early or late embryonic death. Those occurring early should lead to normal cycles, whereas those occurring later would fit into the 46 day interval (Perry et al., 2005).

Parity plays a large role in the incidences of disease in cattle. This study found the greater the parity the more likely for a disease occurrence, which also was observed by BonnevilleHebert et al., (2011). The data indicate that younger cows were able to recover faster and were not as likely to develop health disorders. In this study, all 3 cows in their $5^{\text {th }}$ lactation developed a disease, and only one became pregnant. In addition, those cows in their $5^{\text {th }}$ lactation were clearly selected for their longevity in the herd due to either high milk yields or less frequency of disease compared to other cattle that were culled or not considered for rebreeding because cows with increasing parity are at an increased risk of being sub-fertile, diseased, or deceased. This is a complicated matter due to the amount of time and money spent raising a heifer and then acknowledging that she is likely to have departed before reaching her $5^{\text {th }}$ lactation. This circumstance is detrimental to the farm business and the overall health of that animal is clearly compromised.

Hematocrit varied with a main effect by time but not by BCS category. The pre-breeding time point showed a reduction in hematocrit relative to all other times. Ruginosu et al. (2010) found hematocrit concentrations were reduced from early stage lactation to late stage lactation in healthy cows. Normal hematocrit values of cattle range from 24 to $46 \%$ (Jain et al., 1986), and the range of hematocrit values in this study were 25.1 to $37.1 \%$ with the highest hematocrit at early prepartum ( 0 to $7 \mathrm{~d}$ ). Another study measured packed cell volume and found higher values at parturition and decreasing measurements by day 1 postpartum (Klinkon and Zadnik, 1999). However, they did not follow hematocrit values past $\mathrm{d} 4$. Hence, hematocrit is likely decreasing during at least the first three weeks following parturition and begins to increase by a cow's pregnancy check. Average breeding was 69 DIM and pregnancy check was 26 to $32 \mathrm{~d}$ following breeding, which indicates that hematocrit had increased by 95 DIM. The reduction in hematocrit may be indicative of vitamin or mineral deficiency (possibly insufficient metabolic utilization of the vitamins or minerals), high white blood cell counts and low red blood cell count (anemia), or another stress associated with the blood. 
Pregnancy rate was related to the interaction between Hp measurements at pre-breeding (20 to $26 \mathrm{~d}$ ) and milk yield. Haptoglobin is an APP that is increased during infection and inflammation associated with an APR (Huzzey et al., 2011) and is an indicator of lysis of red blood cells. If red blood cells are being destroyed rapidly, then Hp binds the free hemoglobin and concentration of $\mathrm{Hp}$ is reduced; whereas, the opposite is true in cases of red blood cell or maintenance of normal red blood cell values without increased hemolysis (normal Hp concentrations; Jain, 1986). Increasing concentrations of glucocorticoids, infection, or inflammation cause elevated Hp concentrations (Jain, 1986). Because no relationship was found between hematocrit and Hp at pre-breeding, some cows could be forming an inflammatory response (high $\mathrm{Hp}$ ) to milk production and could be more capable of maintaining a greater immune response. The prebreeding time is important because uterine involution is occurring and the cow is experiencing negative effects of lactation. The APP would be expected to be elevated in cattle that were diseased and maintained at basal values in those that were healthy. The trend observed at pre-breeding in this study is that cows that were diseased were not pregnant, as seen in the high haptoglobin, low milk group. The interesting part is that the highest pregnancy rate was found in the cows with high $\mathrm{Hp}$ and high milk, two variables that would portend suppression in a cow's fertility. Haptoglobin may play a role in increasing the ability of the dairy cow to positively respond to the stresses of inflammation or infection, and, as a result, she is more fertile (52 times more likely to be pregnant to first artificial insemination) than those that do not have as high an inflammatory response, at least when occurring in relation to high milk yield. The interaction between high $\mathrm{Hp}$ / high milk on increasing pregnancy success contradicts the genetic findings associated with gene selection for high milk production having an antagonistic role on fertility (Khatib et al., 2009).

Counts of white blood cells varied with main effect of day but not with the BCS categories. This result conflicts with a study by Rafia et al. (2012), who found significant differences among the same categories of cattle, specifically in lymphocyte counts at $\mathrm{d} 0$ in moderate-conditioned versus over-conditioned and in monocyte counts at d 20 in underconditioned versus over-conditioned cattle. However, overall they did find a significant difference in leukocyte count by category or by day. The differences observed in this study included increasing neutrophils at parturition, which is well documented (Jain et al., 1986). The differences between time 2 ( 0 to $7 \mathrm{~d}$ ) and time 3 (pre-breed 20-26) and time 2 ( 0 to $7 \mathrm{~d}$ ) and time 4 (pregnancy check 26 to 32 post-insemination) were significant for monocyte and neutrophil concentrations. Both of the later times showed reduced counts in the two leukocytes compared to time 2. The number of neutrophils, which are the first defense against foreign invaders and generally comprise $25 \%$ of the total leukocyte population (Paape et al., 2003), remained higher than the other leukocytes at each time point. These data indicate that some form of infection or inflammation was occurring in all categories of cattle at each time point. The observed neutrophilia is similar to the left shift that occurs in an acute inflammation; however, numbers of lymphocytes, which normally decrease in number during a left shift (Jain, 1986), remained the same.

The WBC differential showed that lymphocytes did not vary with time and the concentrations were lower than normal values (normal values $=57$ to $72 \%$ ) while the total neutrophils remained in the higher range of normal (normal values $=20 \%$; Jain, 1986) at each time. The increase in neutrophils at parturition corresponds with findings of Jain (1986); and of Joksimovic and Davidovic (2012). The concentrations of neutrophils were higher and the 
number of lymphocytes were lower than those reported by Nazifi et al. (2008) for cows sampled 25 to $30 \mathrm{~d}$ postpartum, which were consistent with normal values for cattle. The lower than normal lymphocyte numbers may have been due to systemic inflammation in the cattle. Lymphopoenia is observed in cattle during an acute inflammatory response, which would explain the neutrophilia observed during the various time points, especially during parturition when there is a high rate of secretion of glucocorticoids. High CRH can act as an immunosuppressant, but, in some cases, CRH and ACTH stimulation of pituitary and adrenal cortex may be blocked due to inflammatory cytokines (TNFa, IL-1, and IL-6; O'Connor et al., 2000), which may explain the high $\mathrm{Hp} /$ high milk group having a greater conception rate. When comparing the Hp/milk and WBC values it is speculative to say that those cows with the ability to form an inflammatory response are more capable of fighting inflammation or infections associated with mammary and reproductive tissues (i.e. greater immune system), which allows them to be more probable to conceive and maintain pregnancy.

In summary, categorizing animals by BCS in the prepartum did not allow prediction of pregnancy success. Furthermore, although BCS changed from prepartum through early postpartum, the relative change was not associated with success of pregnancy after a Pre-Synch and Ov-Synch protocol. Inseminating cows after estrus tended to increase pregnancy success compared to timed insemination. Cows having disease early postpartum and particularly around d 21 to 26 were less likely to become pregnant at first insemination. Hematocrit was lowest at d 21 to 26 postpartum, corresponding with the lowest BCS, and indicating a time of stress. More sampling times were needed to determine when hematocrit values began to increase from the low values at prebreeding. As reviewed by Jain (1986), high milk producing cows develop anemia more frequently than low milk producing cows. Answers for the differences in the role of APP in inflammatory response are needed and other studies looking at the interaction between Hp and milk yield need to be performed to gain greater knowledge about this association. Higher pregnancy success in regards to high $\mathrm{Hp} /$ high milk is a strategy that needs further investigation to determine the role of the interaction in relation to fertility in dairy cattle.

\section{REFERENCES}

Acin-Perez R., E. Salazar, M. Kamenetsky, J. Buck, L.R. Levin, and G. Manfredi. 2009. Cyclic AMP produced inside mitochondria regulates oxidative phosphorylation. Cell Metab. 9(3):265-76.

Akins, M.S., S.J. Bertics, M.T. Socha, and R.D. Shaver. 2013. Effects of cobalt supplementation and vitamin B12 injections on lactation performance and metabolism of Holstein dairycows. J. Dairy Sci. 96:1755-68.

Ametaj, B.N. 2005.A new understanding of the causes of fatty liver in dairy cows. Advances in Dairy Technology. 17:97-112.

Ametaj, B.N., Q. Zebeli, and S. Iqbal. 2010. Nutrition, microbiota, and endotoxin-related diseases in dairy cows. R. Bras. Zootec. 39: 433-444. 
Barker,A. R., F. N. Schrick, M. J. Lewis, H.H. Dowlen, and S.P. Oliver. 1998. Influence of clinical mastitis during early lactationon reproductive performance of Jersey cows . J. Dairy Sci. 81(5): 1286-1290.

Basoglu, A., N. Baspinar, and A. Coskun. 2014. NMR-based metabolomics evaluation in dairy cows with displaced abomasum. Turk. J. Vet. Anim. Sci. 38: 325-330.

Bauersachs, S. and E. Wolf. 2013. Immune aspects of embryo-maternal cross-talk in the bovine uterus. J. Repro. Immun. 97:20-26.

Beitz, D.C. 2014. Etiology and prevention of fatty liver and ketosis in dairy cattle.25th Annual Florida Ruminant Nutrition Symposium. February 4-5, 2014.

Bender K., S. Walsh, A.C.O. Evans, T. Fair, and L. Brennan. 2010. Metabolite concentrations in follicular fluid may explain differences in fertility between heifers and lactating cows. Reproduction 139: 1047-55.

Berezi, I., A. Quintanar-Stephano, and K. Kovacs. Cytokines, stress and immunity.2nd edition. Manitoba: CRC Pr I Llc. 2005. Print.

Berg, J.M, J.L. Tymoczko, and L. Stryer.Biochemistry.5th edition. New York: W.H. Freeman and Company, 2001. Print. 601-630.

Bionaz, M., S. Chen, M.J. Khan, and J.J. Loor. 2013. Functional role of PPARs in ruminants: potential targets for fine-tuning metabolism during growth and lactation. Hindawi Publishing Corp. PPAR Research. 1-28.

Bonneville-Hebert, A., E. Bouchard, D.D. Tremblay, and R. Lefebvre. 2011. Effect of reproductive disorders and parity on repeat breeder status and culling of dairy cows in Quebec. The Canadian J. of Vet. Res. 75:147-151.

Bradford B.J. 2012. Nutrition and immunity. Proceedings Tristate Nutrition Conference.

Busillo J.M. and J.A. Cidlowski. 2013. The five Rs of glucocorticoid action during inflammation: ready, reinforce, repress, resolve, and restore. Trends in Endocrinology and Metabolism. 24(3):109-119.

Butler, S.T., A.L. Marr, S.H. Pelton, R.P. Radcliff, M.C. Lucy, and W.R. Butler. 2003. Insulin restores $\mathrm{GH}$ responsiveness during lactation induced negative energy balance in dairy cattle: effects on expression of IGF-1 and GH receptor 1A. J. Endocrinol. Feb; 176(2): 205-17.

Butler, W.R. 2012.The role of energy balance and metabolism on reproduction of dairy cows. 23rd Annual Ruminant Nutrition Symposium.From ASAS.

Cardeso, F.C., S.J. LeBlanc, M.R. Murphy, and J.K. Drackley. 2013. Prepartum nutritional strategy affects reproductive performance in dairy cows. J. Dairy Sci. 96: 5859-5871.

Combs, G. F. The Vitamins. 2nd edition. San Diego: Academic Press, 1998. Print. pp. 403-420. 
DeFrain, J.M., M.T. Socha, D.J. Tomlinson, and D. Kluth. 2009. Effect of complexed trace minerals on the performance of lactating dairy cows on a commercial dairy. Prof. Anim. Sci. 25:709-715.

Demetrio, D. G. B., R. M. Santos, C. G. Demetrio, and J. L. Vasconcelos. 2007. Factors affecting conception rates following artificial insemination or embryo transfer in lactating Holstein cows. J. Dairy Sci. 90:5073-5082.

Domecq, J.J., A. L. Skidmore, J. W. Lloyd, and J.B. Kaneene. 1997. Relationship between body condition scores and conception at first artificial insemination in a large dairy herd of high yielding Holstein cows. J. Dairy Sci. 80(1): 113-120.

Drackley, J.K. 2004. Physiological adaptations in transition dairy cows. Proc. Minnesota Dairy Herd Health Conf., St. Paul, MN. University of Minnesota, St. Paul. 74-87.

Ebdalabadi, M.N., R. Valizadah, A.H. Moussavi, M.D. Mesgaran, M. Tahmoorespour, and A. Ehsani. 2014. Effects of timing to start lipogenic diet on productive and reproductive responses in periparturient dairy cows. Livestock Science 162: 104-114.

Esposito, G., P.C. Irons, E.C. Webb, and A. Chapwanya. 2014. Interactions between negative balance, metabolic diseases, uterine health and immune response in transition dairy cows. Anim. Repro. Sci. 144:60-71.

Ferguson, J. D., D.T. Galligan, and N. Thomsen. 1994. Principal descriptors of body condition score in Holstein cows. J. of Dairy Science. 77:2695-2703.

Galvao,K. M. Felippe, S. Brittin, R. Sper, M. Fraga, J. Galvao, L. Caixeta, C. Guard, A. Ricci, R. Gilbert. 2012. Evaluation of cytokine expression by blood monocytes of lactating Holstein cows with or without postpartum uterine disease. Theriogenology. 77: 356-372.

Garverick, H.A., M.N. Harris, R. Vogel-Bluel, J.D. Sampson, J. Bader, W.R. Lamberson, J.N. Spain, M.C. Lucy, and R.S. Youngquist. 2013. Concentrations of nonesterified fatty acids and glucose in blood of periparturient dairy cows are indicative of pregnancy success at first insemination. J. Dairy Sci. 96:181-88.

Grummer, R.R., D.G. Mashek, A. Hayirli. 2004. Dry matter intake and energy balance in the transition period. Vet. Clin. Food Anim. 20: 447-470.

Grummer, R.R. 2008. Nutritional and management strategies for the prevention of fatty liver in dairy cattle.The Veterinary Journal. 176(1):10-20.

Hammon, D., I. Evjen, T. Dhiman, J. Goff, J. Walters. 2006. Neutrophil function and energy status in Holstein cows with uterine health disorders. Vet. Immunol.Immunopathol. 113: 21-29.

Hansen, P.J. 2011. Challenges to fertility in dairy cattle: from ovulation to the fetal stage of pregnancy. Rev. Bras. Reprod. Anim. 35(2): 229-238.

Hernandez-Ceron, J., C. G. Gutierrez-Aguilar. 2013. Recombinant bovine somatotropin and reproduction in cattle, sheep, and goat. Agrociencia. 47:35-45. 
Huzzey, J.M., D.V. Nydam, R.J. Grant, and T.R. Overton. 2011. Associations of prepartum plasma cortisol, haptoglobin, fecal cortisol metabolites, and nonesterified fatty acids with postpartum health status in Holstein dairy cows. J. Dairy Sci. 94: 5878-5889.

Inskeep, E.K. 2004.Preovulatory, postovulatory, and postmaternal recognition effects of concentrations of progesterone on embryonic survival in the cow. J. Anim. Sci. 82(E. Suppl.): E24-E39.

Inskeep, E.K. and R.A. Dailey. 2005. Embryonic Death in Cattle. Vet. Clin. Food Anim. 21: 437-461.

Inskeep, E.K., M.M. Oloufa, A.L. Pope and L.E. Casida. 1963. Functional capabilities of experimentally-induced corpora lutea ewes. J. Animal Sci. 22:159-161.

Izadyar, F., W.J. Hage, B. Colenbrander, and M.M. Bevers. 1998. The promontory effect of growth hormone on the developmental competence of in vitro matured bovine oocytes is due to cytoplasmic maturation. Mol. Reprod. Dev. 49: 444-453.

Jain, N.C. Schalm's Veterinary Hematology.4th Edition. Philadelphia: Lea and Febiger, 1986. Print. 178-204.

Joksimovic, M.T. and V. Davidovic. 2012. Changes in white blood pictures and some biochemical parameters of dairy cows in peripartum period and early lactation. Mljekarstvo. 62(2): 151-58.

Kennedy, D. G., A. Cannavan, A. Molloy, F. O’Harte, S. M. Taylor, S. Kennedy, and W. J. Blanchflower. 1990. The activity of methylmalonyl-CoA mutase (EC 5.4.99.2) and methionine synthetase (EC 2.1.1.13) in the tissues of cobalt-vitamin B12 deficient sheep. Br. J. Nutr. 64:721-732.

Kennedy, D. G., S. Kennedy, W. J. Blanchflower, J. M. Scott, D. G. Weir, A. M. Molloy, and P. B. Young. 1994a. Cobalt-Vitamin B12 deficiency causes accumulation of oddnumbered, branched-chain fatty acids in the tissues of sheep. Br. J. Nutr. 71:67-76.

Kennedy, D. G., P. B. Young, W. J. Blanchflower, J. M. Scott, D. G. Weir, A. M. Molloy, and S. Kennedy. 1994b. Cobalt-vitamin B12 deficiency causes lipid accumulation, lipid peroxidation and decreased á-tocopherol concentrations in the liver of sheep. Internat. J. Vit. Nutr.Res. 64:270 276.

Khafipour, E., S. Li, and D.O. Krause. 2009. Rumen microbiome composition determined using two nutritional models of subacute rumen acidosis. Appl. Environ. Microbiol. 75(22): 7115-24.

Khatib, H., C. Maltecca, R. L. Monson, V. Schutzkus, and J. J. Rutledge. 2009. Monoallelic maternal expression of STAT5A affects embryonic survival in cattle. BMC Genet. 10(13): 1471-2156.

Kimura, K., Reinhardt, T.A., Goff, J.P. 2006. Parturition and hypocalcemia blunts calcium signals in immune cells of dairy cattle. J. Dairy Sci. 89: 2588-2595. 
Klinkon, M. and T. Zadnik. 1999. Dynamics of red and white blood picture in dairy cows during the periparturient period. Comp. Hematol. Int. 9: 156-161.

Krause, A.R.T., L.F.M. Pfeifer, P. Montagner, M.M. Weschenfelder, E. Schwegler, M. E. Lima, E.G. Xavier, C.C. Brauner, E. Schmitt, F.A.B. Del Pino, C.F. Martins, M.N. Correa, and A. Schneider. 2014. Associations between resumption of postpartum ovarian activity, uterine health and concentrations of metabolites and acute phase proteins during the transition period in Holstein cows. Anim. Repro. Sci. 145:8-14.

Kropp, J., F. Penagaricano, S.M. Salih, and H. Khatib. 2014. Invited review: Genetic contributions underlying the development of preimplantation bovine embryos. J. Dairy Sci. 97: 1187-1201.

Kuzmina, T.I., H. Alm, V. Denisenko, A. Tuchscherer, W. Kanitz, and H. Torner. 2007. Effect of recombinant bovine somatotropin (rBST) on cytoplasmic maturation of bovine oocytes and their developmental competence in vitro. J. Repro. Dev. Apr; 53(2): 309-16.

LeRoy, J.L.M.R., T. Vanholder, B. Mateusen, A. Christophe, G. Opsomer, A de Kruif, G. Genicot, and A. V. Soom. 2005. Non-esterified fatty acids in follicular fluid of dairy cows and their effect on developmental capacity of bovine oocytes in vitro. Reproduction. 130:485-95.

Li G., E.J. Barrett, M.O. Barrett, W. Cao, Z. Liu. 2007. Tumor necrosis factor-alpha induces insulin resistance in endothelial cells via a p38 mitogen-activated protein kinasedependent pathway. Endocrinology. Jul; 148(7):3356-63.

Loor, J.J. 2010.Genomics of metabolic adaptations in the peripartal cow.The Animal Consortium. 4(7): 1110-39.

Lucy, Matthew C. 2012. Growth hormone regulation of follicular growth.Reproduction, Fertility, and Development. 24:19-28.

Martinez-Patino, N., C.A. Risco, F. Maunsell, K.N. Galvão, and J.E. Santos. 2011. Presentation at the 44th Annual Conference of the American Association of Bovine Practitioners, St. Louis, Missouri, September 22-24, 2011.

Matthews, R. G. 1999. Cobalamin-dependent methionine synthase.Pages 681-706 in Chemistry and Biochemistry of B12. R. Banerjee, ed. John Wiley \& Sons, inc., New York.

Merck Animal Health. 2012. Reproduction in Cattle Physiology. http://www.partners-in-reproducition.com/reproduction-cattle/physiology-intro.asp Visited on: March 28, 2013.

Miller, Alan L. 2003. The methionine-homocysteine cycle and its effects on cognitive diseases. Alternative Medicine Review.8(1): 7-19.

Morales-Roura, J.S., Zarco, L., Hernandez-Cer'on, J., Rodriguez, G., 2001.Effect of short-term treatment with bovine somatotropin at estrus on conception rate and luteal function of repeat- breeding dairy cows. Theriogenology 55, 1831-1841. 
Nagaraja, T.G., E.E. Bartley, L.R. Fina. 1978. Relationship of rumen gram-negative bacteria and free endotoxin to lactic acidosis in cattle. J. Anim. Sci. 80(6): 1329-36.

Nazifi, S., M.R. Ahmadi, and H.R. Gheisari. 2008. Hematological changes of dairy cows in postpartum period and early pregnancy. Comp. Clin. Pathol. 17: 157-163.

NRC, National Research Council. 2001. 7th revised edition. Nutrient Requirements of Dairy Cattle. Electronic version.

O’Connor, T.M., D.J. O'Halloran, F. Shanahan. 2000. The stress response and the hypothalamicpituitary-adrenal axis: from molecule to melancholia. QJM. 93(6): 323-333.

Oetzel, G.R. and B.E. Miller. 2012. Effect of oral calcium bolus supplementation on earlylactation health and milk yield in commercial dairy herds. J. Dairy Sci. 95:7051-7065.

Paape, M.J., D.D. Bannerman, X. Zhao, and J.W. Lee. 2003. The bovine neutrophil: Structure and function in blood and milk. Vet Res. 34(5): 597-627.

Perry, G.A., M. F. Smith, M.C. Lucy, J. A. Green, T. E. Parks, M.D. MacNeil, A.J. Roberts, and T.W. Geary.2005 Relationship between follicle size at insemination and pregnancy success. PNAS 102: 5268-5273.

Preis, K.A., G.J. Seidel, and D.K. Gardner. 2005. Metabolic markers of developmental competence for in vitro-matured mouse oocytes. Reproduction. 130: 475-83.

Rabelo, E., R.L. Rezende, S.J. Bertics, R.R. Grummer. 2005. Effects of pre- and postfresh transition diets varying in dietary energy density on metabolic status of periparturient dairy cows. J. Dairy Sci. 88(12): 4375-4383.

Ramalho-Santos, J.R., S. Varum, S. Amaral, P. C. Mota. A.P. Sousa, and A. Amaral. 2009. Mitochondrial functionality in reproduction: from gonads and gametes to embryos and embryonic stem cells. Human Reproduction. 15(5): 553-572.

Ruginosu, E., St. Creanga, M. Sofronie, A. Anton, Gh. Solcan. 2010. The hematologic profile of cattle with reproductive diseases. CercetariAgronomice in Moldova. 43(2):142.

Santschi, D.E., R. Berthiaume, J.J. Matte, A.F. Mustafa, and C.L. Girard. 2005. Fate of supplementary B-vitamins in the gastrointestinal tract of dairy cows. J. Dairy Sci. 88(6): 2043-2054.

Schemm, S.R., D.R. Deaver, L.C. Griel Jr., and L.D. Muller. 1990. Effects of recombinant bovine somatotrophin on luteinizing hormone and ovarian function in lactating dairy cows. Biol.Of Repro. 42:815-21.

Selye, H.A. 1936. A syndrome produced by diverse nocuous agents. Nature. 138: 32.

Sinclair, K.D. 2010. Declining fertility, insulin resistance and fatty acid metabolism in dairy cows: Developmental consequences for the oocyte and pre-implantation embryo. Acta Scientiae Veterinariae. 38 (Supl 2): s545-s557 
Shaum, K.M., A.J. Polotsky. 2013. Nutrition and reproduction: is there evidence to support a "Fertility Diet" to improve mitochondrial function?. Marturitas. 74(4): 309-312.

Speeckaert, M., Huang, G., Delanghe, J.R., Taes, Y.E., 2006, Biological and clinical aspects of the vitamin D binding protein (Gc-globulin) and its polymorphism. ClinChimActa 372: $33-42$.

Spencer, T.E. 2013. Early pregnancy: Concepts, challenges, and potential solutions. Animal Frontiers 3(4): 48-55

Squires, E.J. Applied Animal Endocrinology. Cambridge: CABI Publishing. 2003. Electronic version. pp. 1-120.

Sreenan, J., M. Diskin, and D. Morris. 2001. Embryo survival rate in cattle: a major limitation to the achievement of high fertility. In Fertility in the High-Yielding Dairy Cow, pp 93104. BSAS Occasional Publication 26, Scotland, UK: British Society of Animal Science.

Stangl, G.I., F.J. Schwarz, H. Müller, and M. Kirchgessner. 2000. Evaluation of the cobalt requirement of beef cattle based on vitamin B12, folate, homocysteine, and methylmalonic acid. Brit. J. Nutr. 84:645-653.

Tamadon, A., M. Kafi, M. Saeb, A. Mirzaei, and S. Saeb. 2011. Relationships between insulinlike growth factor-I, milk yield, body condition score, and postpartum luteal activity in high-producing dairy cows. Trop. Anim. Health Prod. 43:29-34.

Tiffany, Mark Elton. 2003. Cobalt Requirements of Growing and Finishing Cattle Based On Performance, Vitamin B12 Status and Metabolite Concentrations. North Carolina State University Dissertation.

Tucker, H.A. 2000. Symposium: Hormonal regulation of milk synthesis. J. Dairy Sci. 83:874884.

Uchoa, E.T., G. Aguilera, J. P. Herman, J. L. Fiedler, T. Deak, and M. B. Cordeiro de Sousa. 2014. Novel aspects of glucocorticoid actions. J. Neuroendocrinol. 1365-2826

USDA- Animal Improvement Program Laboratory. 2014. Decline in Fertility. http://aipl.arsusda.gov/eval/summary/trend.cfm.

Vasconcelos, J. L. M., S. Sangsritavong, S. J. Tsai, and M. C.Wiltbank.2003. Acute reduction in serum progesterone concentration after feed intake in dairy cows. Theriogenology 60:795-807.

Walsh, S.W., E.J. Williams, A.C.O. Evans. 2011. A review of the causes of poor fertility in high milk producing dairy cows. Anim. Repro. Sci. 123 (3-4): 127-138.

Ward, G., G. B. Marion, C. W. Campbell, and J. R. Dunham. 1971. Influences of calcium intake and vitamin D supplementation on reproductive performance of dairy cows. J. Dairy Sci. 54: 204-206. 
Wathes, D.C., A.M. Clempson, and G.E. Pollott. 2013. Associations between lipid metabolism and fertility in the dairy cow. Reproduction, Fertility and Development. 25:48-61.

Weiss, W.P. and G. Ferreira. 2006. Are your cows getting the vitamins they need?.WCDS Advances in Dairy Technology.Electronic form.

Weiss, B. 2005. Update on vitamin nutrition of dairy cows. Ruminant Health and Nutrition Conference. New England Dairy Feed Conference. Electronic Version.

Weiss, W.P. and G. Ferreira. 2010. Water soluble vitamins for dairy cattle. eXtension. Ohio Agricultural Research and Development Center. http://www.extension.org/pages/11443/watersoluble-vitamins-for-dairy-cattle

Yuan K, Farney JK, Mamedova LK, Sordillo LM, Bradford BJ. 2013. TNF $\alpha$ altered inflammatory responses, impaired health and productivity, but did not affect glucose or lipid metabolism in early-lactation dairy cows. PLoS ONE 8(11): e80316. 